\title{
Climatology and Trends in Hourly Precipitation for the Southeast United States
}

\author{
VINCENT M. BROWN AND BARRY D. KEIM \\ Department of Geography and Anthropology, Louisiana State University, Baton Rouge, Louisiana \\ ALAN W. BLACK \\ Department of Geography, Southern Illinois University Edwardsville, Edwardsville, Illinois
}

(Manuscript received 8 January 2019, in final form 25 April 2019)

\begin{abstract}
This research introduces a climatology of hourly precipitation characteristics, investigates trends in precipitation hours $(\mathrm{PH})$ and hourly accumulation, and uses four different time series to determine if precipitation intensity is changing across the southeastern United States from 1960 to 2017. Results indicate hourly intensity significantly increased at $44 \%(22 / 50)$ of the stations, accompanied by an increase in average hourly accumulation at $40 \%$ of the sites analyzed (20/50). The average duration of precipitation events decreased at $82 \%(41 / 50)$ of the stations. However, the frequency of 90 th percentile hourly events and events above station-specific average hourly totals did not show a broad increase similar to hourly intensity. It seems hourly events are becoming heavier on average, while the duration of the average precipitation event is decreasing. Geographically, heavy hourly events are more frequent along the Gulf Coast and decrease inland. PH significantly decreased across South Carolina, Georgia, and northern Florida, mainly due to significant decreases in winter (DJF) and spring (MAM). Decreases in PH during spring were contained to Georgia and South Carolina and were accompanied by a decrease in accumulation. Decreases in PH during winter were more widespread and did not exhibit a broad decrease in accumulation, suggesting winter precipitation across that portion of the region is becoming more intense.
\end{abstract}

\section{Introduction}

Precipitation across the southeastern United States (hereafter SeUS) varies substantially from year to year. For example, in 2007 an extreme drought struck parts of Georgia, Alabama, eastern Tennessee, and the Carolinas, followed by excessive rainfall and flooding in roughly the same area in 2009, both of which caused catastrophic economic loss (Manuel 2008; Maxwell and Soulé 2009; Gotvald and McCallum 2010). This inherent variability has a large effect on the hydrologic cycle, and small shifts in precipitation totals, intensity, and duration impact runoff, soil moisture, and crop yields in the region (Karl and Riebsame 1989). Total accumulation, which represents an aggregation of rainfall characteristics, is often used to quantify precipitation and is a vital metric for agriculture, freshwater resources, and water availability. However, using accumulation alone omits a large portion of the precipitation story, such as cause, type, duration, and intensity. These variables are

\footnotetext{
Corresponding author: Vincent M. Brown, vbrow31@1su.edu
}

condensed into one quantity and summed over a day, month, season, or year to define precipitation, primarily because most precipitation data are recorded daily (Zolina et al. 2010, 2013; Trenberth et al. 2017). Daily data are critical to our understanding of precipitation, but its intermittent nature highlights the need to quantify other characteristics such as frequency, intensity, and duration, which do not operate at the daily scale (Trenberth and Zhang 2017). For example, most severe and extreme storms are associated with short periods of intense rainfall (Muschinski and Katz 2013) that are not apparent when examining daily data.

To better understand the significance of projected climatic change, the historical record of variability must be investigated so anticipated conditions can be placed in a longer-term perspective (Bradley et al. 1987). It is known that the intensity of precipitation events changes with temperature according to the Clausius-Clapeyron equation (Trenberth et al. 2003). In fact, intensity has been observed to increase more than mean precipitation (totals) under a warmer climate (Trenberth et al. 2003) and is one of the more detectable aspects of a changing 
hydrologic cycle (Hegerl et al. 2015; Wang et al. 2017). Precipitation extremes are also projected to become more frequent (Chou et al. 2012; Kirtman et al. 2013; Fischer and Knutti 2015), primarily related to changes in thermodynamic processes (Emori and Brown 2005; Maloney et al. 2014; Prein et al. 2017). Recent work by Skeeter et al. (2019) found significant increases in extreme precipitation events across portions of the SeUS; thus, necessitating the examination of subdaily events to determine if they are changing in conjunction with daily and multiday events.

While parts of the SeUS experienced a "warming hole" or an absence of warming compared to other regions in the United States during the past century (Rogers 2013), temperatures in the region have increased by roughly $2^{\circ} \mathrm{F}$ since the 1970 s and diurnal temperature ranges have decreased broadly, primarily due to rising minimum temperatures (USGCRP 2014; Powell and Keim 2015; USGCRP 2017). With scientific consensus asserting the global climate has and will continue to warm (see Kirtman et al. 2013; USGCRP 2017) and given the recent observed temperature changes (shrinking daily temperature range, increases in minimum temperatures; see USGCRP 2017) across the SeUS, it is plausible to expect a response in precipitation; however, trends in precipitation have been difficult to detect. Detection is challenging because of inherent variability, but locations in the SeUS have generally experienced more precipitation in less time (USGCRP 2017; Powell and Keim 2015) and extreme precipitation events have become more frequent in recent decades (Kunkel 2003; USGCRP 2017; Skeeter et al. 2019). Subdaily data that allow for the investigation of precipitation characteristics are needed to better understand the direct effects a changing climate may have on precipitation in the SeUS.

The goal of this research is to examine precipitation characteristics using hourly data to better understand subdaily precipitation across the SeUS. No such climatology exists to date, and only recently has work been started on rain day climatology. In particular, this research focused on the frequency of precipitation hours $(\mathrm{PH})$, duration of events, intensity, and hourly totals. Frequency and duration are important for agriculture and vegetation, while intensity and rainfall rates relate to flooding risks (Trenberth and Zhang 2017).

This analysis expands upon previous research on trends in precipitation (e.g., Burauskaite-Harju et al. 2012; Powell and Keim 2015; Fu et al. 2016) by examining hourly precipitation data at 50 first-order weather stations across the SeUS. Previous studies (Groisman and Easterling 1994; Karl et al. 1993; Skeeter et al. 2019) focused on accumulations when determining change, but variations in accumulation could be the result of more hours with precipitation, more intense events, or a unique combination of changes in frequency, duration, and intensity. This study will

1) introduce an annual and seasonal climatology of the frequency of PH across the SeUS,

2) investigate the average duration and intensity of hourly rainfall annually and seasonally, and

3) develop time series of hourly precipitation characteristics to test for trends in the annual and seasonal frequency of hours with precipitation and amounts, change in overall intensity and duration of hourly events, and the frequency of 90th percentile hourly events.

\section{Study region}

This research investigates the spatiotemporal characteristics of precipitation across the SeUS (Fig. 1). The region was selected because it frequently experiences extreme events (Kunkel et al. 2012, 2013b; Keim et al. 2018), is highly vulnerable to a changing climate (Powell and Keim 2015; Carter et al. 2018), is a leading producer of important crops such as oranges, cotton, tobacco, rice, and vegetables (USDA 2016), and matches the study region used by Henderson and Vega (1996), Keim (1997), and Powell and Keim (2015). The region constitutes the southeastern quadrant of the conterminous United States.

Composed of eleven states-Alabama, Arkansas, Florida, Georgia, Louisiana, Mississippi, North Carolina, Oklahoma, South Carolina, Tennessee, and Texas-the SeUS is classified as humid subtropical (excluding western Texas/Oklahoma and southern Florida), but seasonal and annual distributions of precipitation vary substantially (Fig. 2). Coastal locations along the Gulf of Mexico (GOM) receive around $1524 \mathrm{~mm}$ (60 in.) of precipitation annually, while central locations in the Carolinas and Georgia receive between 1016 and $1270 \mathrm{~mm}$ (40-50 in.) (Kunkel et al. 2013a). The highest annual average accumulation occurs near southwestern North Carolina along the Tennessee border where totals often exceed $2540 \mathrm{~mm}(100 \mathrm{in}$.); the lowest totals are found in western Texas and Oklahoma, where less than $508 \mathrm{~mm}$ (20 in.) are received annually. Variability is largely explained by daytime convective rainfall (Kunkel et al. 2013a), the strength and position of the Bermuda high, particularly in summer (Li et al. 2011, 2012; Diem 2013; Zhu and Liang 2013), proximity to and sea surface temperatures (SSTs) of the GOM (Trenberth 1998; Trenberth et al. 2003) and Atlantic Ocean, tropical cyclones (Keim 1996; Nogueira and Keim 2010, 2011; Nogueira et al. 2013), and local 


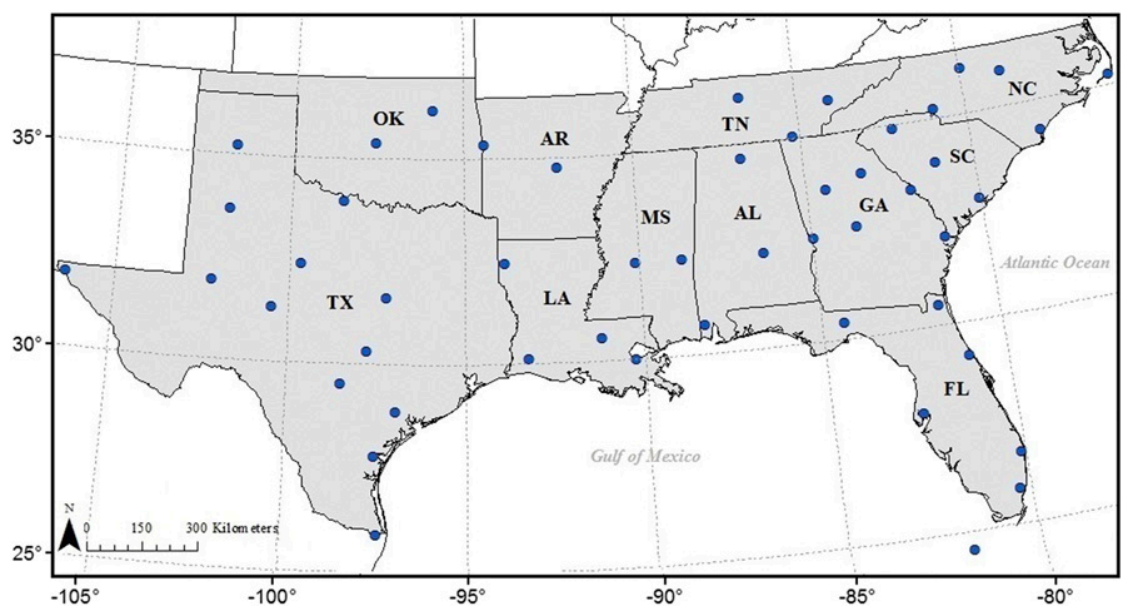

FIG. 1. The 11-state region selected for this study. Blue dots represent the location of firstorder weather stations used for testing trends (50 in total). An additional six stations were used to create climatology figures (not pictured).

topography. Tropical cyclones, which are important to the climatology (Simpson and Riehl 1981; Nogueira et al. 2013) and cause extreme precipitation events in the SeUS (Kunkel et al. 2012), were not controlled for or removed.

\section{Data}

Data for this research come from 50 first-order weather stations (Fig. 1) that are maintained by the National Centers for Environmental Information (NCEI) within the Hourly Precipitation Database (HPD). The HPD provides time-sequenced hourly precipitation totals for a network of over 7000 reporting stations primarily located in the United States (NOAA 2016). The HPD is available on a station-by-station basis and returns all hours with recorded rainfall including traces in local standard time. Only first-order weather stations, which provide reliable, quality controlled, hourly observations at long temporal scales, were selected for this analysis.

Following methods from Brown et al. (2019), precipitation time series were created for each station. Initially, the year 1950 was selected as the start date for the time series because a large number of first-order stations across the region and United States were moved to airports around that time. By 1950, a majority of the stations were operational, thus providing a uniform

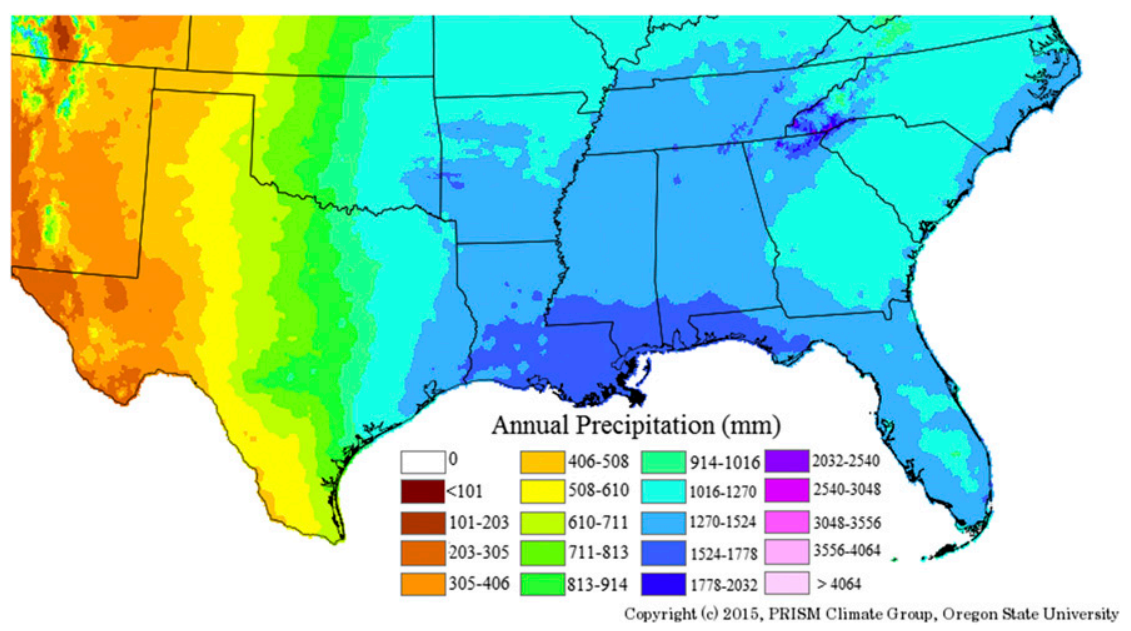

FIG. 2. Annual average precipitation of the SeUS 1981-2010. Source PRISM Climate Group, supported by USDA Risk Management Agency and Northwest Alliance for Computational Science and Engineering (NACSE) based at Oregon State University. (C) 2018, PRISM Climate Group, Oregon State University, http://prism.oregonstate.edu; map created 2015. 
starting point; however, some stations have gaps early in the record and others did not come online until the 1960s. For these reasons and to ensure a large enough sample size, first-order weather stations with continuous hourly precipitation data starting in 1960 (58 years) were used.

To ensure the data were reliable, hourly (totals) observations (from the HPD) for each station were summed by year to attain an annual total. These annual data were compared to the Local Climatological Data (LCD) publication that archives some of the most reliable precipitation data available. In most cases, precipitation totals from hourly and daily data agree; however, they may disagree for a number of reasons, including under catchment by automated hourly stations or missing hourly data. One requirement of this study is a continuous time series for each station where the hourly observations of each year sum to within $\pm 10 \%$ of the reported LCD annual precipitation total from daily data, a threshold selected to follow methods in Brown et al. (2019). It is known that in the HPD some stations do not meet the $\pm 10 \%$ requirement for certain years. It is important to note that most hourly accumulation time series captured less precipitation ( $\mathrm{mm}$ ) compared to the observed daily data; thus, capturing at least $90 \%$ of the daily data annually was often the goal. For example, at Baton Rouge Ryan Airport (KBTR) in 1985, there are multiple rain days with missing hourly data. To avoid sacrificing the entire station's dataset because of a few missing observations, two other data sources were used, the Midwestern Regional Climate Center (MRCC) and the Iowa Environmental Mesonet (IEM).

The first supplementary dataset is the MRCC's hourly precipitation database. This database also reports hourly precipitation in local standard time. Hourly rainfall totals from the MRCC database are usually the same as the HPD but sometimes (often due to different quality control techniques) contain observations that are not present in the HPD. The MRCC data helped add observations to years when the HPD data did not meet the $90 \%$ requirement; however, the Regional Climate Center data are very similar to the HPD. Often if data are missing in the HPD, they are also missing in the Regional Climate Center data. This was the case with KBTR data from 1985, when hourly data from both datasets only summed to roughly $88 \%$ of the reported annual total in the LCD annual report from daily data.

To attain the $90 \%$ threshold, a second supplementary data source was used. This source is the IEM raw METAR data. Hourly precipitation totals from METAR are reported at varying times, often at $53 \mathrm{~min}$ past the hour and can also contain other special observations, which can lead to differing hourly totals (between raw METAR and final HPD) during PH without careful analysis. In some cases, especially during heavy rainfall, the hourly reported IEM data differ from both MRCC and HPD data by a few millimeters. Differing totals between the NCEI LCD annual and monthly reports and summed hourly data can often be attributed to a few individual months, or just a few days within a given year (i.e., a severe weather event), as was the case in 1985 at KBTR. Therefore, individual months or days where HPD or MRCC data are clearly missing or lacking were replaced with IEM METAR data. This was performed manually on a station-by-station basis by identifying periods (first months then days) in which HPD or MRCC hourly data differed from the LCD daily reports. The IEM data were only used for years in which the annual precipitation totals from the other two hourly sources were below $90 \%$ of the annual totals based on daily data. Within these years, the IEM data were only substituted for the specific months (or days) where precipitation totals from the hourly data were below $90 \%$ of the totals from daily data. For example, if the June 1990 LCD from daily data recorded $254 \mathrm{~mm}$ (10 in.) of precipitation but the HPD hourly data only summed to $203.2 \mathrm{~mm}$ (8in.) $(80 \%)$ then the day(s) in which the missing totals occurred would be replaced with IEM data. This was easily identifiable using the LCD daily reports.

The differing time collection method used in the IEM and its automated nature introduces slight biases (i.e., undercatchment, tipping-bucket issues, systematic errors) but enabled the construction of a continuous hourly precipitation time series where all years capture $\geq 90 \%$ of the edited annual LCD report values. It is important to note that most years at each station using the HPD alone contained $\geq 95 \%$ of the annual precipitation total. Also of importance is the treatment of trace values. Trace values represent a wet gauge but no measureable accumulation and were removed from this analysis.

\section{Limitations of data}

The likelihood that a particular gauge captures the true amount of precipitation produced by an event is extraordinarily low. Gauge measurements tend to underestimate true precipitation, largely due to wind turbulence at the gauge orifice and wetting loss on the inside walls of the gauge (Groisman and Legates 1994). The catch of gauges decreases as wind speeds increase, and errors are larger with snow (Legates and DeLiberty 1993). Legates and DeLiberty (1993) estimated the average bias in gauge measurements across the United States is roughly $9 \%$, with higher biases found in locations that receive frequent snow and reside at high 
elevations due to less friction. However, Legates and DeLiberty (1993) found stations in the SeUS tend to have the lowest bias compared to other regions, with an average bias of less than $8 \%$.

Another limitation of in situ precipitation data is caused by station relocation and gauge type. Periodic relocation of stations can induce discontinuities in precipitation time series and, along with other biases discussed above, may limit the ability to detect changes in the hydrologic cycle or climate change (Groisman and Legates 1994). Keim et al. (2003) investigated relocation bias and its impact on temperature measurements and asserted that it is likely these biases also exist in precipitation time series. When a precipitation gauge is moved, it is probable the vegetation, proximity to buildings, or elevation also changed. A consequence of such movement is changes in wind flow characteristics near the gauge, which can affect gauge catchment (Eischeid et al. 1991). It is also important to understand that gauges periodically get replaced or upgraded. An example can be seen in the hourly gauge at Louis Armstrong New Orleans International Airport in Louisiana, which has changed four times since 1950. Originally the airport housed a universal rain gauge, followed by a tippingbucket, then an automated heating tipping-bucket, and finally, an all-weather precipitation accumulation gauge. This may seem detrimental to any analysis attempted, but all records of equipment type and relocation are well documented. It is also important to keep in mind the strict quality control standards maintained by the National Weather Service (NWS). The NWS requires that stations not be moved more than $8 \mathrm{~km}(5 \mathrm{mi})$, nor change elevation $\pm 30 \mathrm{~m}(100 \mathrm{ft})$, to be considered compatible with the original station location. This ensures that precipitation measurements are as reliable and consistent as possible (NOAA 2012).

Trepidations regarding the accuracy of gauge measurements are a problem in any analysis and although no dataset is perfect, the HPD is one of the more reliable sources of hourly precipitation (Brooks and Stensrud 2000). As stated above, the likelihood a gauge captures the true precipitation total of an event is extremely low. To avoid this bias, this analysis focused on $\mathrm{PH}$. $\mathrm{PH}$ are binary, meaning it is either raining or not. It is likely $\mathrm{PH}$ have less biases when compared to precipitation totals.

\section{Methods}

Data from the HPD and the supplemental sources were used to create time series of $\mathrm{PH}$ and precipitation totals on an annual and seasonal basis. Regression, which is widely used in precipitation research (Kunkel et al. 1999; Groisman et al. 2012; Skeeter et al. 2019; etc.), was implemented using the created time series to determine if long-term trends existed in annual and seasonal $\mathrm{PH}$ and precipitation totals time series for each station. The residuals for each stations time series were tested for normality-an assumption of regression (Montgomery and Peck 1982) —using the Shapiro-Wilk test (Shapiro and Wilk 1965). Residuals for some of the times series (e.g., stations in Texas where near-zero precipitation during a season can occur) were not normally distributed and exhibited $p$ values $<0.05$; however, small deviations from normality do not affect the regression model as it is robust when errors in normality are present (Montgomery and Peck 1982). Further evaluation using normal Q-Q, residual versus fitted, and scale-location plots revealed approximate normality and added confidence to the regression tests performed on the time series with time (year) as the independent variable and the number of $\mathrm{PH}$ or totals as the dependent variable. An example of one regression equation is as follows:

$$
(\text { winter } \mathrm{PH})=b_{0}+b_{1}(\text { year }) \text {. }
$$

To investigate changes in hourly precipitation intensity, four separate time series were created for each station, all on an annual basis. First, the average annual hourly intensity was calculated for each station by adapting the simple daily intensity index for hourly data (Powell and Keim 2015; Brown et al. 2019). The simple daily intensity index is calculated by dividing the annual precipitation total by the number of days with precipitation (defined as any day with precipitation $>0 \mathrm{~mm}$ ) as a measure of intensity. Similarly, the annual hourly intensity was calculated by dividing the annual precipitation total by the number of $\mathrm{PH}$ in that given year.

Second, time series of average hourly accumulation were created by averaging each hourly observation (only on hours where precipitation $>0.254 \mathrm{~mm}$ ) within each year. The frequency distribution of hourly precipitation amounts resembles a Poisson or right skewed distribution, with the highest frequency occurring at $0.254 \mathrm{~mm}(0.01 \mathrm{in}$.) and decreasing in frequency as magnitude increases (Fig. 3). The nature of the hourly precipitation distribution does not allow for considerable deviation in the mode or median; however, the mean will more noticeably shift up or down when changes in precipitation occur (i.e., more or less intense precipitation in a year) and provides a good indication of changes in the distribution.

Third, a time series of the frequency of hours with totals above the overall average hourly accumulation was created. For example, the average hourly accumulation using all hourly observations (1960-2017) with 


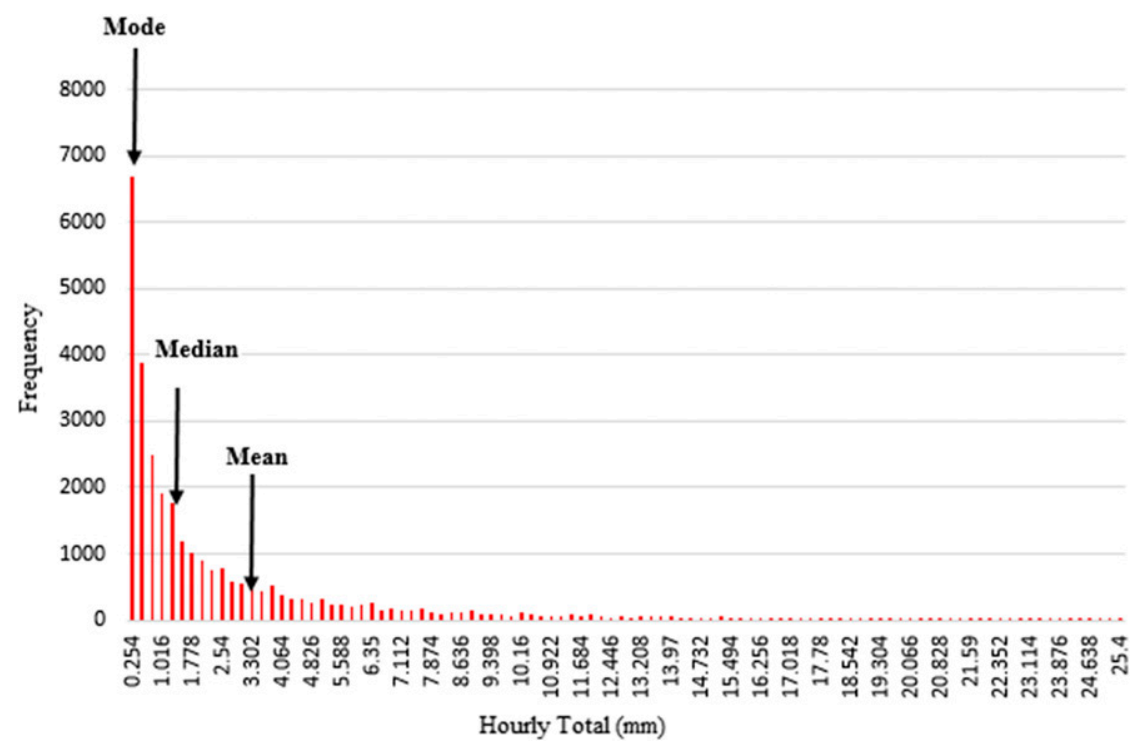

FIG. 3. Example of typical hourly precipitation distribution. The highest frequency (mode) occurs at $0.254 \mathrm{~mm}(0.01 \mathrm{in}$.), the median at $1.27 \mathrm{~mm}(0.05 \mathrm{in}$.), and the mean at $3.30 \mathrm{~mm}$ (0.13 in.).

precipitation at Baton Rouge (KBTR) is $3.3 \mathrm{~mm}$ (0.13 in.). The number of times an hourly precipitation total was greater than this station specific average hourly total was recorded for each year of the time series to determine if above average hourly totals are occurring more frequently through time.

The annual frequency of 90th percentile hourly events was used to determine if the top $10 \%$ of hourly events were changing through time. This metric is of interest because Karl and Knight (1998) found increases in precipitation mostly due to changes in the top $10 \%$ of the distribution, where the total precipitation attributed to heavy and extreme events increased at the expense of moderate events. Furthermore, Prein et al. (2017) asserted extreme hourly precipitation events should increase significantly across the United States in areas with abundant moisture, such as the SeUS. Each 90th percentile threshold was calculated on a station-by-station basis based on the time series of hourly precipitation amounts. One disadvantage of the percentile-defined approach becomes evident when the time series is ranked because a large range of values exist at the far right of the distribution that can differ by tens of millimeters (Groisman et al. 2012); however, for this analysis the focus is on the frequency of events surpassing station specific thresholds, not exact hourly totals.

The annual duration of precipitation events was investigated by averaging the duration of all precipitation events within each year. Using hourly precipitation data, durations have to be expressed in hourly increments (Robinson and Henderson 1992). While the occurrence of measured precipitation in an hour does not assure continuous precipitation or even that a single event occurred, it is impossible to separate those events (Robinson and Henderson 1992). Robinson and Henderson (1992) discussed how the length of dry periods between events is not self-evident and that synoptic analysis by Thorp and Scott (1982) suggest that there is no single correct value to separate events. However, for climatological and hydrological uses, a single consistent separation interval (or $1 \mathrm{~h}$ ) is desirable (Robinson and Henderson 1992). In this research, if measureable precipitation was recorded, it was labeled as an event and the length of the event depended on how many consecutive hours' measurable precipitation occurred. In each year, for each station, the average duration of events was calculated by determining each individual event duration and summing each, then dividing by the annual frequency of individual events. This helps determine if annual event durations are changing through time. Each of the time series were tested for normality for use in regression.

\section{Kriging and natural break classification}

To visualize spatial (climatological) patterns in precipitation characteristics, spatial interpolation via ordinary kriging with natural break classification in ArcGIS 10.5 was used. Interpolation was necessary due to the sparseness of reliable, long-term hourly station data. The eleven state region covers roughly $2066712 \mathrm{~km}^{2}$ $\left(797962 \mathrm{mi}^{2}\right)$. If the stations were equally spaced, there would be one station for every $36905 \mathrm{~km}^{2}\left(14249 \mathrm{mi}^{2}\right)$ making this one obvious limitation of the analysis. 

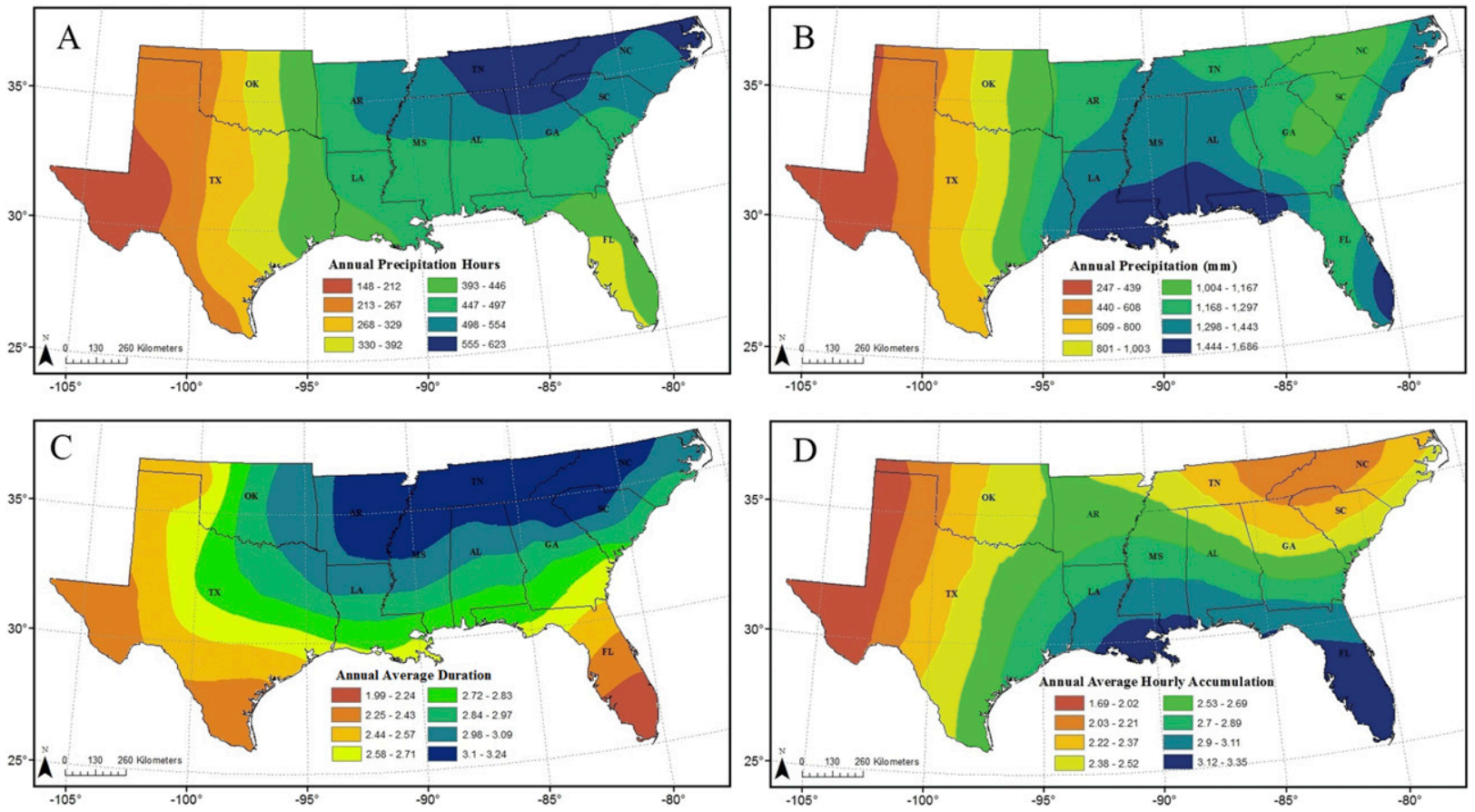

FIG. 4. Annual precipitation characteristics: (a) annual average precipitation hours, (b) annual precipitation accumulation (mm), (c) annual average precipitation duration, and (d) average annual hourly precipitation accumulation ( $\mathrm{mm}$ ).

Kriging, a geostatistical technique for optimal spatial estimation (Waller and Gotway 2004; Ozturk and Kilic 2016), uses the statistical properties of the stations precipitation characteristics, quantifies the spatial autocorrelation of the station points, and accounts for the configuration of the points around the estimated location(s) (Matthews 2002; Ozturk and Kilic 2016). The distance between stations is assumed to reflect spatial correlation that can be used to explain variation in the estimated surface (Oliver and Webster 1990). One limitation of this approach in addition to the distances between points is topography, which is not accounted for and can lead to over simplification of local precipitation characteristics in mountainous areas of the region.

These maps are used to generalize precipitation characteristics across the SeUS and have limitations in interpretation because of the sparseness of data points. This limitation can be seen when comparing Fig. 2, which is generated (1981-2010) from a relatively dense station network (daily data) and incorporates digital elevation models and other spatial datasets (Daly et al. 1997), and Fig. 4b, generated from hourly data at 56 firstorder weather stations (1960-2017). To generate Fig. 4b and subsequent climatology maps, six additional stations were used with slightly differing starting dates (between 1965 and 1970) to fill gaps in data-sparse areas. These stations were only used for the climatological maps to better fill in data gaps and to aid in visualizing patterns across the SeUS. These stations were not used in any other part of the temporal analyses.

The highest annual average precipitation accumulation in the region, located along the border of eastern Tennessee and western North Carolina in the Appalachian Mountains, is not evident in Fig. 4b. Higher accumulations in the Ouachita Mountains of western Arkansas are also not captured because of the relatively sparse station density. The spatial patterns shown in the generated climatological maps are only as good as the spatial resolution of the stations. While local precipitation characteristics and spatial patterns are greatly simplified, the kriged annual accumulation map from hourly data largely identifies the same precipitation patterns as Fig. 2. This lends confidence to all the interpolated precipitation maps. For more information on kriging see Matthews (2002), Waller and Gotway (2004), and Ozturk and Kilic 2016, as well as the Environmental Systems Research Institute (ESRI) website.

Natural breaks (Jenks 1967) were used to classify the categories for each precipitation characteristic. The natural breaks method classifies data values into separate "bins" based on breaks or naturally occurring gaps in the data (Jiang 2013). This optimization minimizes within-class variance and maximizes between class variations simultaneously (Jenks 1967) and is known as the goodness-of-variance fit method (Jiang 2013). 


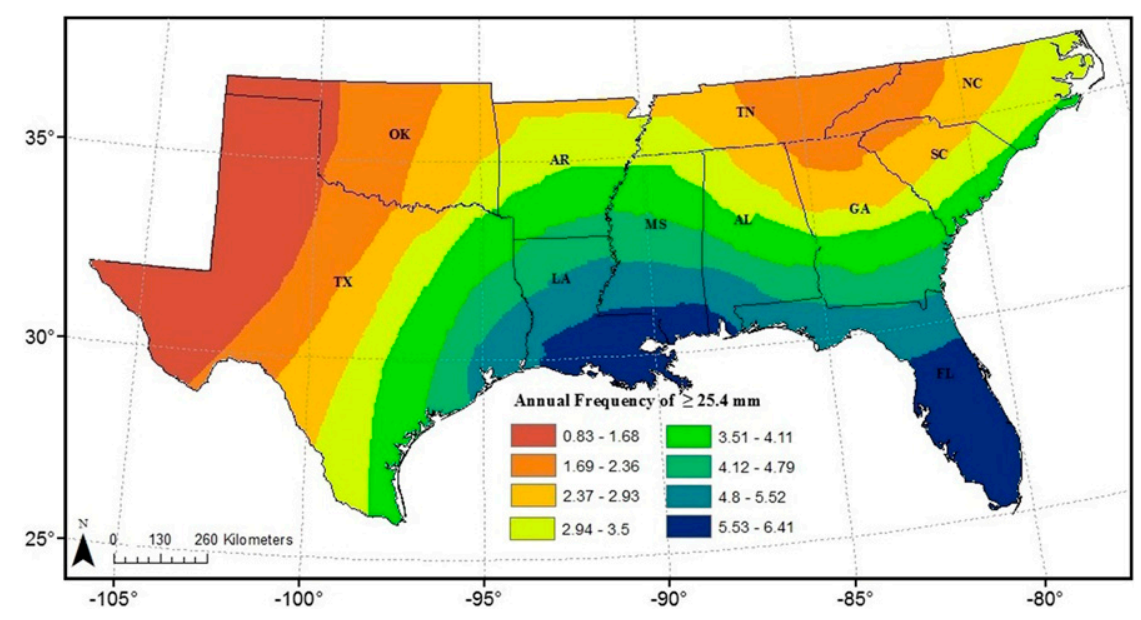

FIG. 5. Average annual frequency of $25.4 \mathrm{~mm}$ ( $1 \mathrm{in}$.) or greater events, derived by frequency of events divided by station period of record.

This approach is widely used in statistical mapping (see Chen et al. 2013 and Jiang 2013). For more information on natural breaks see Jenks (1967).

\section{Results}

\section{a. Annual climatology}

Using kriging and natural breaks classification in ArcGIS 10.5, a map of average annual PH across the SeUS was created (Fig. 4a). Results indicate stations in eastern Tennessee and western North Carolina experience the most $\mathrm{PH}$ annually, while stations in western Oklahoma and Texas receive the least. Louisiana and northern Florida experience a similar number of $\mathrm{PH}$ and a large east to west gradient is prevalent across Texas. Comparing Figs. $4 \mathrm{a}$ and $4 \mathrm{~b}$, it is evident that precipitation characteristics vary substantially across the region. For example, southern Louisiana, Mississippi, and Alabama tend to accumulate more precipitation compared to the rest of the region, excluding orographically forced precipitation over eastern Tennessee and southwestern North Carolina that is not resolved in Fig. 4b, but do not experience the most $\mathrm{PH}$. This is the result of differing hourly precipitation intensities and durations produced by varying synoptic conditions that cause precipitation in the region.

The average annual duration of precipitation events (Fig. 4c), which are not confined to the daily scale, follows a similar spatial pattern as PH. Florida, a precipitation regime dominated by summer afternoon convection, and western Texas, the driest sector of the region, have the shortest precipitation event durations on an annual basis. Gulf Coast stations also exhibit lower annual durations compared to stations across the northeastern tier of the region. These stations (across Tennessee and North Carolina) receive more $\mathrm{PH}$ but less accumulation resulting in less intense precipitation that persists for a longer duration. This pattern is reflected in average hourly accumulations (Fig. 4 d), which are roughly $25 \%$ higher across the Gulf Coast and Florida compared to the western and northeastern portions of the region, and the average annual frequency of $25.4 \mathrm{~mm}$ (1 in.) or greater hourly events (Fig. 5). The Gulf Coast and Florida average approximately twice as many $25.4 \mathrm{~mm}$ (1 in.) or greater hourly events annually compared to the rest of the region.

\section{b. Seasonal climatology}

Seasonally, the locations that receive the most $\mathrm{PH}$ shifts dramatically. In winter (DJF), the $\mathrm{PH}$ maximum is located in eastern Tennessee and along the Appalachian Mountains (Fig. 6a), due to slow moving frontal events, orographic uplift, and cold air damming events (Bell and Bosart 1988; Rackley and Knox 2016). This area is also where the annual snowfall maxima is located for the SeUS (Kunkel et al. 2013a). However, the highest accumulations are located in Louisiana, Mississippi, and Alabama (Fig. 6b). Southern Florida experiences similar PH frequencies as parts of Texas, mainly due to a shift in storm tracks (Klein 1957; Whittaker and Horn 1984) that shield Florida from precipitation events. Average durations in winter follow a similar pattern as PH (Fig. 6c), where Florida and Texas have shorter average durations compared to most of the region. Longer duration events in the northeastern sector of the region are related to frontal events that often bring snow (Keim 1996). Gulf Coast locations exhibit shorter durations compared to interior locations but have higher average hourly accumulations 

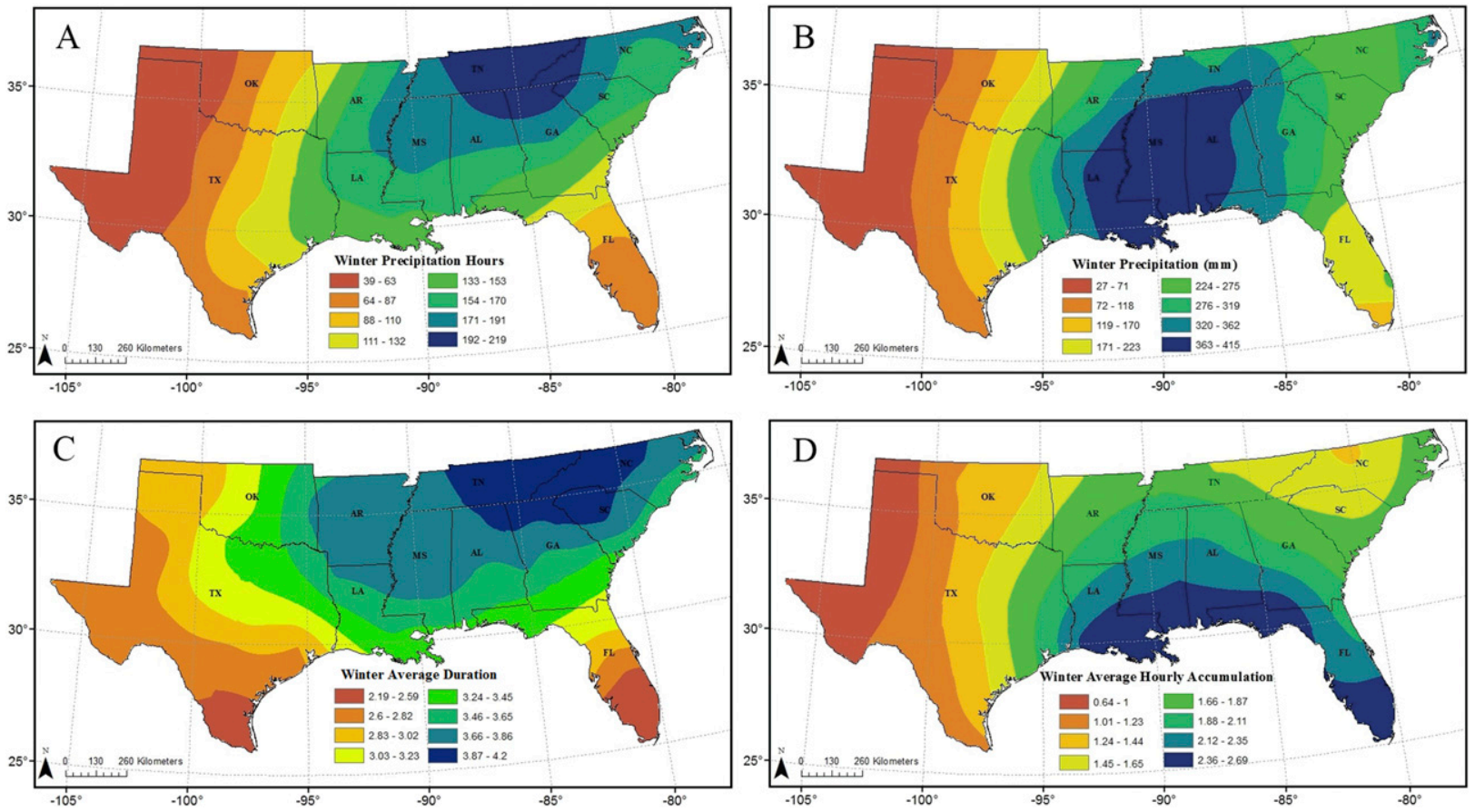

FIG. 6. Winter (DJF) precipitation characteristics: (a) average precipitation hours, (b) precipitation accumulation (mm), (c) average precipitation duration, and (d) average winter hourly precipitation accumulation ( $\mathrm{mm}$ ).

(Fig. 6d), highlighting the intensity of winter precipitation across the Gulf Coast. Nonetheless, winter is when most stations experience the longest average duration of precipitation events, primarily due to frequent frontal events (Keim 1996).

In spring (MAM), $\mathrm{PH}$ are more frequent in the northern portion of the region (Fig. 7a). A north to south gradient exists from northern Tennessee to the Gulf Coast. Texas, again, exhibits a large east to west gradient, and Florida experiences below-average PH frequencies compared to the rest of the region. Accumulations in spring are highest across Mississippi, central Arkansas, and western Tennessee (Fig. 7b), where inflow from the Gulf of Mexico provides moisture for passing fronts and storms. Precipitation totals decrease east and west of central Mississippi, a gradient in the opposite direction of $\mathrm{PH}$.

The average duration of events in spring (Fig. 7c) is similar to winter with longer durations found in the northern sector and shorter durations in Texas and Florida. The slightly above average durations across Oklahoma and Arkansas are related to severe weather outbreaks and mesoscale convective complexes (Ashley et al. 2003) that impact those states in spring. Average hourly accumulations (Fig. 7d) resemble annual and winter patterns as well. The Gulf Coast stations have higher hourly accumulations compared to the rest of the region.
In summer (JJA) a large shift in $\mathrm{PH}$ is observed. Gulf and Atlantic coastal stations, as well as Florida, experience the greatest PH (Fig. 8a), coinciding with high accumulation (Fig. 8b). This rainfall is largely attributed to daytime convective storms that gather moisture from the nearby water bodies and tend to be somewhat intense (Fig. 8d). Across Florida, rising air along sea breeze fronts also produces substantial rainfall (Kunkel et al. 2013a). Average event durations (Fig. 8c) are not congruent with PH frequencies or accumulation. Stations along the Gulf Coast and extending inland, which accumulate substantial rainfall, have short average durations. Compared to all seasons, summer averaged the shortest event durations, but parts of Texas, Oklahoma, and the Carolinas exhibit relatively longer average durations. The northerly stations are more frequently affected by fronts in summer than locations farther south. Furthermore, Oklahoma stations have higher durations related to mesoscale convective complexes, which are active in the area in the summer (Ashley et al. 2003). Longer durations in Texas (Waco, Austin, and San Antonio) could be related of topography and onshore flow, causing air to rise and precipitation to occur.

During fall (SON), $\mathrm{PH}$ are more frequent in eastern Tennessee and southwestern North Carolina and a minimum exists in western Texas (Fig. 9a). Accumulations are highest in southern Florida and Louisiana (Fig. 9b), 

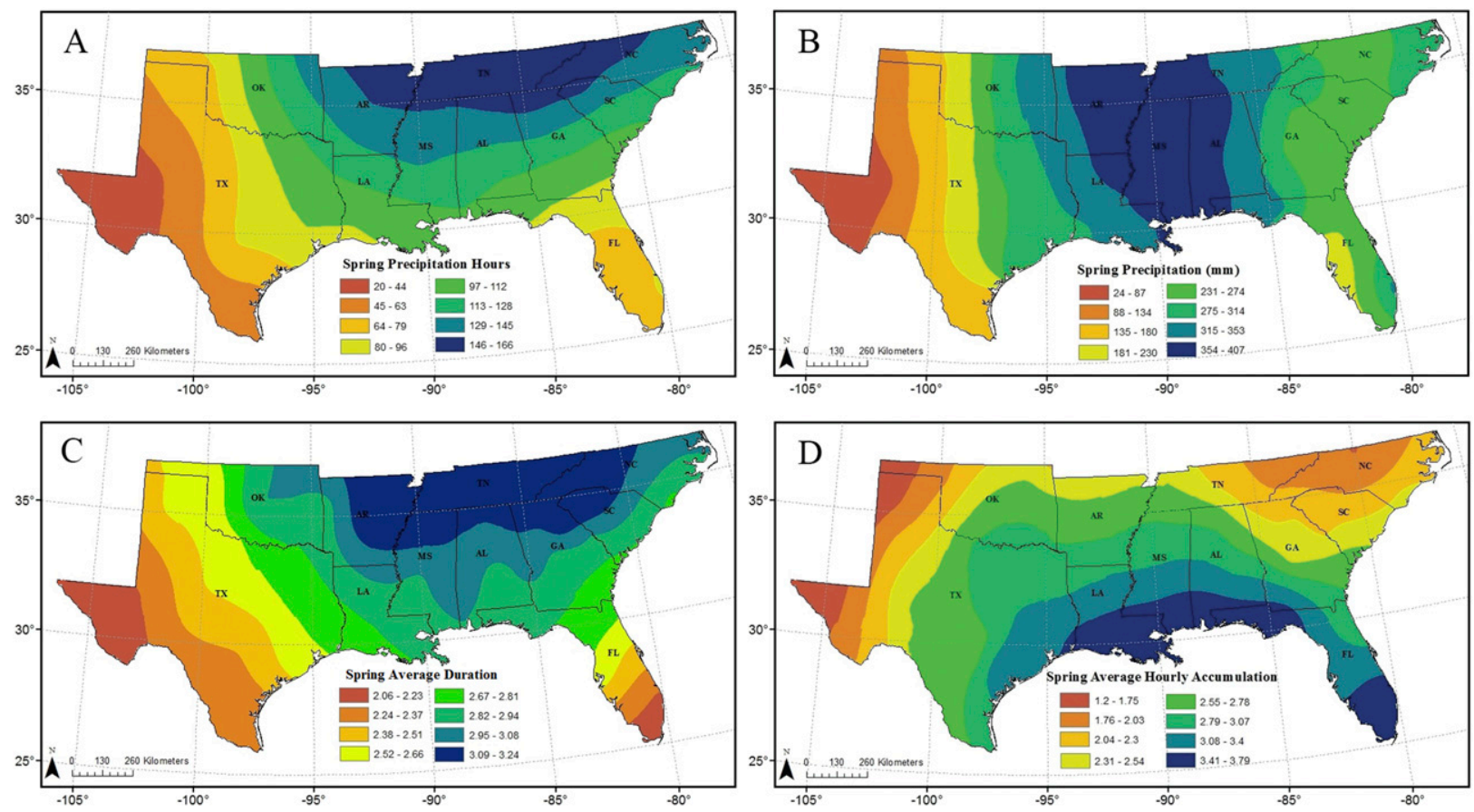

FIG. 7. Spring (MAM) precipitation characteristics: (a) average precipitation hours, (b) precipitation accumulation (mm), (c) average precipitation duration, and (d) average hourly precipitation accumulation ( $\mathrm{mm})$.

likely related to tropical cyclones (Simpson and Riehl 1981; Nogueira et al. 2013). A large gradient exists in PH and accumulation across Texas and Oklahoma linked to moisture availability and cyclogenesis. The average duration of events resembles spring and winter (Fig. 9c). Florida and much of the Gulf Coast have below-average durations, while Tennessee and the western Carolinas have above-average durations. Average hourly accumulations (Fig. 9d) are higher along the Gulf Coast, demonstrating yet again the intensity of events in those areas.

\section{Trends in precipitation hours and totals}

\section{a. Annual}

Fourteen of the 50 stations had statistically significant (defined as a $p$ value $\leq 0.05$ ) trends in the annual frequency of PH (Fig. 10a). Across South Carolina, Georgia, and northern Florida, thirteen stations exhibited significant decreasing trends (of roughly $1.2-2 \mathrm{~h} \mathrm{yr}^{-1}$; Table 1), while two stations had decreasing trends with $p$ values between $0.05 \leq p \leq 0.10$. Annual accumulation trends showed a different pattern. Only five stations had significant trends, of which three were increasing and two decreasing (Fig. 10b). Another six stations had $p$ values between $0.05 \leq p \leq 0.10$, of which four (two) showed increasing (decreasing) trends.
Annual accumulation trends lack a clear spatial pattern excluding the three stations with decreases in Georgia and South Carolina, likely related to the decreases seen in annual precipitation hours. The parameter estimates (change in variable per one unit change in year) and correlation coefficients for each station for annual hours and annual accumulation can be seen in Table 1.

\section{b. Seasonality}

In winter, PH significantly decreased across North Carolina, South Carolina, Georgia, and northern Florida (Fig. 10c). Seventeen stations in that sector and 22 stations overall showed statistically significant decreases in PH. Parameter estimates for PH across Georgia and the Carolinas are between -1.23 and -0.51 , meaning $\mathrm{PH}$ have decreased on average by $0.51-$ $1.23 \mathrm{~h} \mathrm{yr}^{-1}$ since 1960. Winter totals (Fig. 10d) do not reflect this change, as only five stations in the entire region showed a significant decrease in precipitation accumulation. This reveals a change in winter precipitation across that sector, where the frequency of $\mathrm{PH}$ is decreasing but precipitation totals are not, favoring more intense winter precipitation.

In spring, four stations had significant decreasing trends in $\mathrm{PH}$ and another five stations had decreasing trends at the $0.05 \leq p \leq 0.10$ level (Fig. 10e). These stations were located across Georgia and South Carolina 

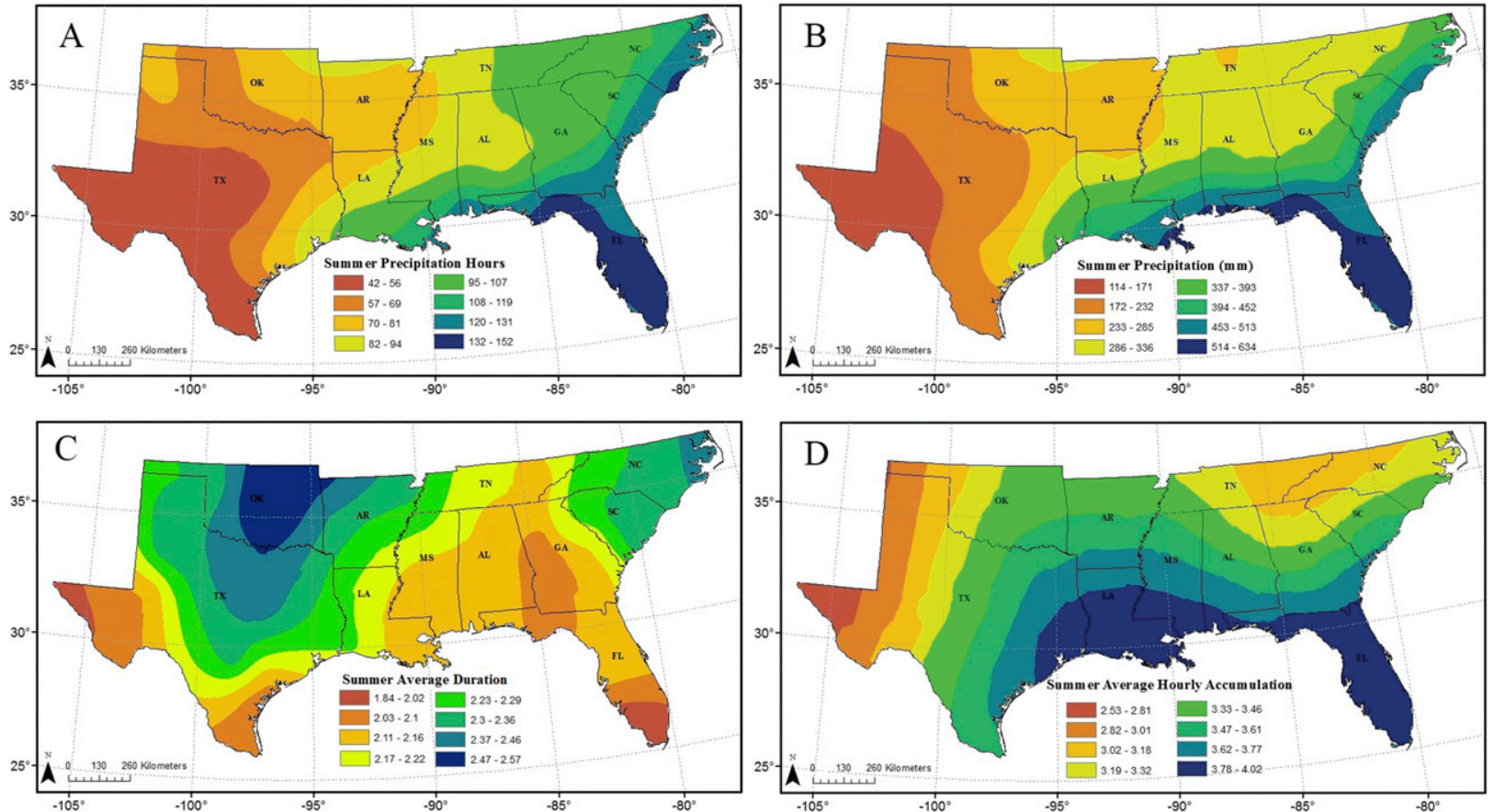

FIG. 8. Summer (JJA) precipitation characteristics: (a) summer average precipitation hours, (b) precipitation accumulation (mm), (c) average precipitation duration, and (d) average hourly precipitation accumulation $(\mathrm{mm})$.

and, generally, exhibited decreases in accumulation (Fig. 10f). It is interesting that the decreases in $\mathrm{PH}$ during spring are accompanied by a decrease in accumulation, whereas the stations that have decreasing $\mathrm{PH}$ in winter do not also exhibit a decrease in accumulation. The decrease in annual PH in Georgia and South Carolina can be attributed to a decrease in $\mathrm{PH}$ during winter and spring, but, the fact annual totals are not broadly decreasing in this sector is unique, especially considering no other season showed increasing totals in that area. This phenomenon could be related to changes in cold-air damming, which peaks in activity during winter and spring and has a large influence on precipitation patterns at stations near Appalachia (Bell and Bosart 1988; Rackley and Knox 2016), or snowfall which has decreased in this general area in the past 50 years (Eck et al. 2019).

During summer, eight stations exhibited significant trends in PH (Fig. 10g). Three east coast stations had decreasing trends, and stations across Louisiana, Mississippi, and southern Florida had increasing trends. Summer accumulations (Fig. 10h) showed an almost identical pattern as $\mathrm{PH}$; however, stations in southern Louisiana and Mississippi saw spatially coherent increases in PH. Finally, during fall, two stations showed significant increasing trends in PH (Fig. 10i) and another three station had increasing trends at the $0.05 \leq p \leq 0.10$ level. These stations were located across the coastal
Carolinas. Similar to summer, fall totals closely mimicked fall PH (Fig. 10j).

\section{Trends in intensity and duration}

Forty-four percent (22 of 50) of the stations exhibited significant increases in annual hourly intensity (Fig. 11a). Another seven stations had increasing trends at the $0.05 \leq p \leq 0.10$ level. However, there does not appear to be a clear spatial pattern. This is in agreement with Powell and Keim (2015) that found a broad increase in daily intensity across the region, providing evidence that precipitation events continue to become more intense. Observed trends in intensity and parameter estimates can be seen in Table 1. Annual intensity (precipitation accumulation divided by precipitation hours) increased for stations Mobile, Alabama (KMOB), and San Angelo, Texas (KSJT), by greater than $0.01 \mathrm{~mm} \mathrm{~h}^{-1} \mathrm{yr}^{-1}$ and had correlation coefficients (intensity versus year) of roughly $r=0.44$. Trends in average hourly total (Fig. 11c) show a similar pattern. Forty percent (20 of 50) of stations had significant increasing trends and another seven stations had increases at the $0.05 \leq p \leq 0.10$ level. Most stations that showed increases in annual hourly intensity also showed increases in hourly totals.

Unlike annual hourly intensity and average hourly totals, the frequency of hours with totals above the station-specific average hourly accumulation did not 

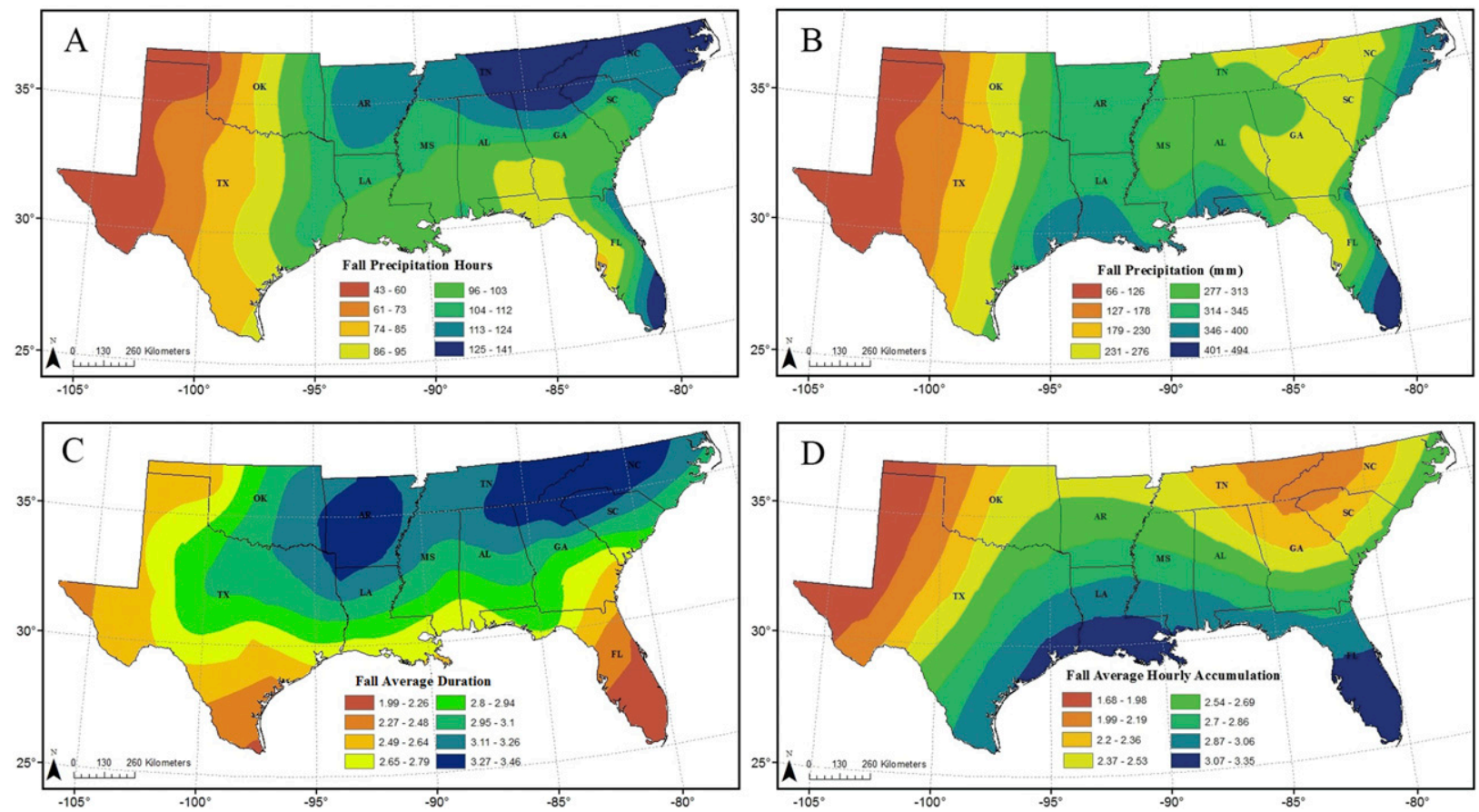

FIG. 9. Fall (SON) precipitation characteristics: (a) average precipitation hours, (b) precipitation accumulation (mm), (c) average precipitation duration, and (d) average hourly precipitation accumulation (mm).

show a broad increase as expected (Fig. 11d). Six stations had significant trends and five were decreasing, located near South Carolina and Georgia, likely related to the decreasing precipitation hours found there. The lack of a broad increase in the frequency of hours above the average hourly total reveals the frequency distribution of hourly precipitation is not changing shape. In fact, it is likely the heaviest hourly events are contributing more rainfall (increasing magnitude). For example, Brown et al. (2019) found, during some years, half of the annual rainfall total at stations in Louisiana could be attributed to 44-47 individual hourly events. This means roughly $0.005 \%$ of the annual hours, or the top $10 \%$ of hourly events, can be responsible for half of the annual accumulation. Brown et al. (2019) also found the frequency of 90th percentile hourly events increased at three of four stations in Louisiana, but this phenomenon seems unique to Louisiana. Across the region, only seven stations had significant trends in the frequency of 90th percentile hourly events: six increasing and one decreasing. Another five stations had increasing trends significant at the $0.05 \leq p \leq 0.10$ level. These results show the change in intensity of hourly precipitation found across the region is not solely attributed to more frequent heavy hourly events. It is likely that increases in the magnitude of hourly events is a larger contributor to the observed increase in hourly intensity compared to more frequent heavy hourly events.
Trends in average event duration revealed $82 \%$ (41 of 50) of the stations experienced a statistically significant decrease in average event duration (Fig. 11b), and one other station [San Antonio, Texas (KSAT)] had a decreasing trend significant at the $0.05 \leq p \leq 0.10$ level. The other eight stations, while not significant, had decreasing trends as well. The significant decreasing trend present at Charlotte Douglas International Airport, North Carolina (KCLT), is a good representation of what is occurring at most stations (Fig. 12a). Arguments can be made that precipitation measurements have vastly improved, leading to the quantification of more 1-h events, which would lower the overall average duration. This systematic error is conceivable, but the fact that only one stations across the region exhibited a significant increasing trend in annual PH demonstrates that gauges are not recording more hours with precipitation. If some type of systematic error or bias does exist due to gauge replacement or improvement, the strength and consistency of the trend, which is apparent at $82 \%$ of the stations in the region, would likely be highly variable and station specific. The residuals from the regression (Fig. 12b) show no pattern and uncorrelated errors; however, further investigation into the observed decrease in average annual duration is needed before systematic or human-induced errors can be completely ruled out.

Decreasing trends in duration could be related to the denominator when calculating average annual durations; 

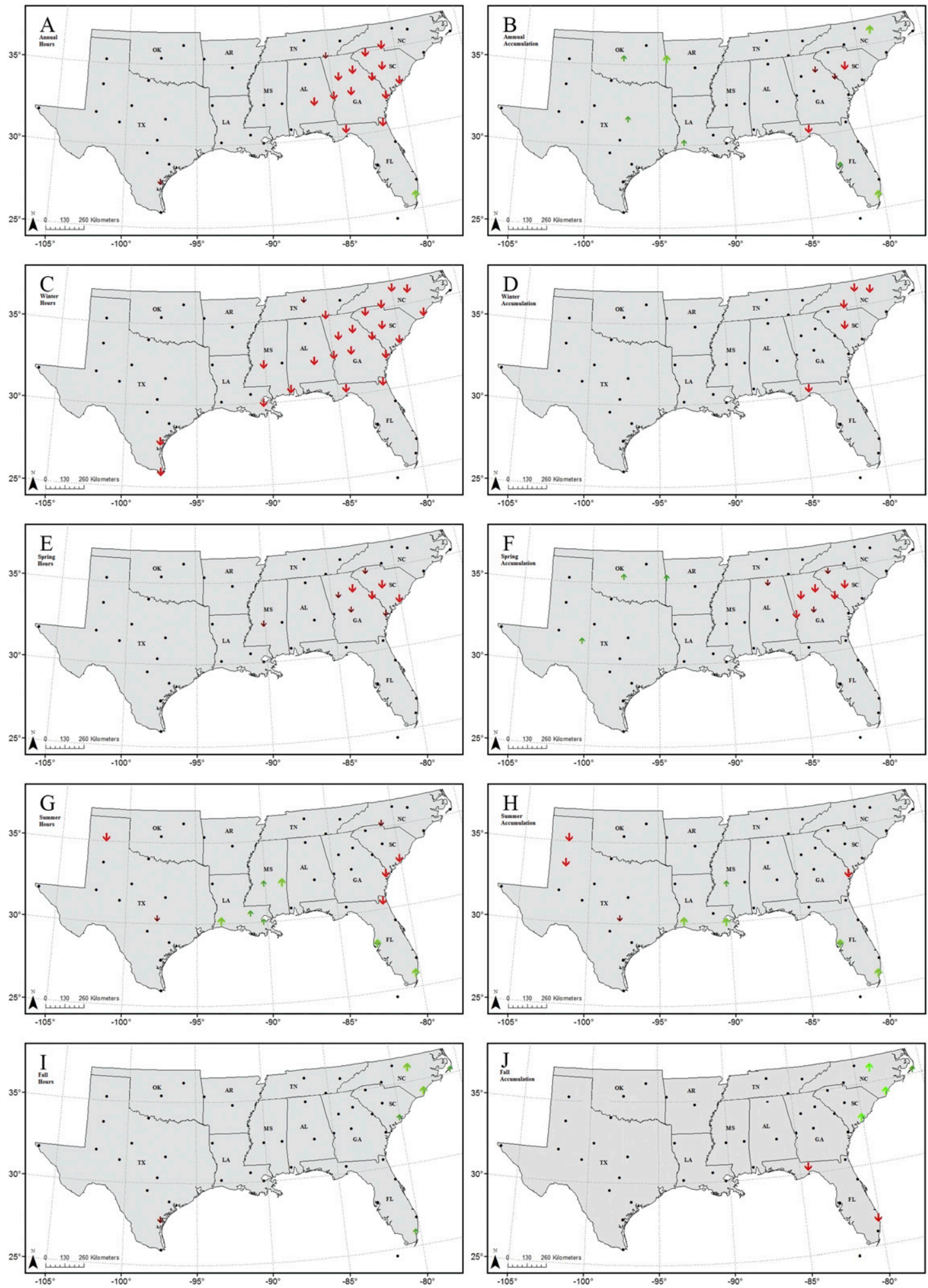

FIG. 10. Trends in (left) PH and (right) accumulation for (a),(b) annual; (c),(d) winter; (e),(f) spring; (g),(h) summer; and (i),(j) fall. Large red arrows represent decreasing trends significant at the $p \leq 0.05$ level; smaller, darker red arrows represent decreasing trends at the $0.05 \leq p \leq 0.10$ level. Large light green arrows represent increasing trends significant at the $p \leq 0.05$ level; smaller, darker green arrows represent increasing trends significant at the $0.05 \leq p \leq 0.10$ level. 
TABLE 1. Annual trend (parameter estimate) and correlation $r$ for PH (columns 3-4), accumulation (columns 5-6), intensity (mm h ${ }^{-1}$; columns 7-8), and duration (hours per event; columns 9-10). Parameter estimates can be interpreted as the change per one unit change in time (year). For example, the parameter estimate for annual hours at CAE is -1.99 , meaning per every one unit increase in year, the number of PH decreases by 1.99 on average. One asterisk $(*)$ corresponds to $p$ values significant at the 0.10 level, two asterisks $(* *)$ denotes significance at the 0.05 level, and three asterisks $(* * *)$ denotes significance at the 0.01 level.

\begin{tabular}{|c|c|c|c|c|c|c|c|c|c|}
\hline \multirow[b]{2}{*}{ Station } & \multirow[b]{2}{*}{ State } & \multicolumn{2}{|c|}{$\mathrm{PH}$} & \multicolumn{2}{|c|}{ Accumulation } & \multicolumn{2}{|c|}{ Intensity } & \multicolumn{2}{|c|}{ Duration } \\
\hline & & $\begin{array}{l}\text { Parameter } \\
\text { estimate }\end{array}$ & $r$ & $\begin{array}{c}\text { Parameter } \\
\text { estimate }\end{array}$ & $r$ & $\begin{array}{l}\text { Parameter } \\
\text { estimate }\end{array}$ & $r$ & $\begin{array}{l}\text { Parameter } \\
\text { estimate }\end{array}$ & $r$ \\
\hline HSV & AL & -0.71 & -0.16 & -2.02 & -0.14 & -0.0002 & -0.02 & $-0.0081 * * *$ & $-0.39 * * *$ \\
\hline MGM & $\mathrm{AL}$ & $-1.17 * *$ & $-0.28 * *$ & -0.82 & -0.06 & $0.0056^{*}$ & $0.25 *$ & $-0.0095 * * *$ & $-0.37 * * *$ \\
\hline MOB & $\mathrm{AL}$ & -0.51 & -0.11 & 3.61 & 0.21 & $0.011 * * *$ & $0.44 * * *$ & -0.0025 & -0.16 \\
\hline FSM & AR & 0.32 & 0.07 & $4.2 * *$ & $0.29 * *$ & $0.0083^{* * *}$ & $0.35^{* * *}$ & $-0.0042 * *$ & $-0.26^{* *}$ \\
\hline LIT & AR & 0.07 & 0.02 & 1.35 & 0.09 & 0.0026 & 0.15 & $-0.005^{* *}$ & $-0.3^{* *}$ \\
\hline DAB & FL & -0.42 & -0.11 & 0.27 & 0.02 & 0.0046 & 0.18 & $-0.0065^{* * *}$ & $-0.49 * * *$ \\
\hline $\mathrm{JAX}$ & FL & $-1.33 * *$ & $-0.31 * * *$ & -1.1 & -0.07 & $0.007 * *$ & $0.29 * *$ & -0.0021 & -0.17 \\
\hline KEY & FL & -0.39 & -0.12 & 0.18 & 0.01 & $0.0063^{* *}$ & $0.21 *$ & -0.0017 & -0.16 \\
\hline MIA & FL & $1.3 * *$ & $0.32 * * *$ & $5.98 * * *$ & $0.35 * * *$ & 0.0039 & 0.16 & $-0.0024 * *$ & $-0.26^{* *}$ \\
\hline PBI & FL & 0.53 & 0.12 & -0.74 & -0.04 & $-0.0057^{*}$ & $-0.24^{*}$ & $-0.0032 * * *$ & $-0.36^{* * *}$ \\
\hline TLH & FL & $-1.16^{* *}$ & $-0.27 * *$ & $-6.6^{* * *}$ & $-0.35 * * *$ & -0.0044 & -0.18 & $-0.009 * * *$ & $-0.51 * * *$ \\
\hline TPA & FL & 0.54 & 0.18 & $3.41 *$ & $0.24 *$ & 0.0051 & 0.18 & -0.0021 & -0.16 \\
\hline AGS & GA & $-1.77 * * *$ & $-0.36^{* * *}$ & $-2.4^{*}$ & $-0.23^{*}$ & $0.0039 *$ & $0.22 *$ & $-0.0133 * * *$ & $-0.54 * * *$ \\
\hline $\mathrm{AHN}$ & GA & $-1.6^{* *}$ & $-0.3 * *$ & $-3.69 *$ & $-0.26^{*}$ & 0.0006 & 0.04 & $-0.0141 * * *$ & $-0.65^{* * *}$ \\
\hline ATL & GA & $-1.31 * *$ & $-0.26^{* *}$ & -0.99 & -0.08 & $0.0039 * *$ & $0.28 * *$ & $-0.009 * * *$ & $-0.56^{* * *}$ \\
\hline CSG & GA & $-1.27 * *$ & $-0.27 * *$ & -2.89 & -0.18 & 0.0009 & 0.05 & $-0.0133 * * *$ & $-0.65 * * *$ \\
\hline $\mathrm{MC}$ & GA & $-1.59 * *$ & $-0.33 * * *$ & 0.21 & 0.02 & $0.008 * * *$ & $0.48 * * *$ & $-0.0073 * * *$ & $-0.41 * * *$ \\
\hline SAV & GA & $-1.76 * * *$ & $-0.44 * * *$ & -2.43 & -0.17 & $0.006^{*}$ & $0.26^{*}$ & $-0.0044 * *$ & $-0.29 * *$ \\
\hline BTR & LA & 0.15 & 0.04 & 3.41 & 0.19 & $0.0062 * *$ & $0.26^{* *}$ & $-0.0076^{* * *}$ & $-0.46^{* * *}$ \\
\hline $\mathrm{LCH}$ & LA & 0.76 & 0.17 & $4.21 *$ & $0.24 *$ & 0.0042 & 0.15 & $-0.0085^{* * *}$ & $-0.45 * * *$ \\
\hline MSY & LA & -0.46 & -0.1 & 2.38 & 0.12 & $0.0087 * *$ & $0.33 * * *$ & $-0.0063^{* * *}$ & $-0.39 * * *$ \\
\hline SHV & LA & -0.07 & -0.02 & 3.45 & 0.2 & $0.0083^{* * *}$ & $0.36^{* * *}$ & $-0.0056^{* *}$ & $-0.29 * *$ \\
\hline JAN & MS & -0.79 & -0.19 & 0.88 & 0.05 & $0.0075^{* *}$ & $0.29 * *$ & $-0.0103^{* * *}$ & $-0.58 * * *$ \\
\hline MEI & MS & 0.64 & 0.15 & 0.25 & 0.02 & -0.0031 & -0.14 & $-0.0131 * * *$ & $-0.54 * * *$ \\
\hline CLT & $\mathrm{NC}$ & $-1.23 * *$ & $-0.28 * *$ & -0.67 & -0.06 & $0.0034^{*}$ & $0.24 *$ & $-0.0129 * * *$ & $-0.7 * * *$ \\
\hline GSO & $\mathrm{NC}$ & -0.73 & -0.18 & -0.14 & -0.01 & 0.0034 & 0.16 & $-0.0102 * * *$ & $-0.55 * * *$ \\
\hline HSE & $\mathrm{NC}$ & 0.35 & 0.07 & 2.62 & 0.16 & 0.0032 & 0.17 & $-0.009 * * *$ & $-0.47 * * *$ \\
\hline ILM & $\mathrm{NC}$ & -0.26 & -0.07 & 2.56 & 0.2 & $0.0059 * *$ & $0.26^{* *}$ & $-0.0069 * * *$ & $-0.46 * * *$ \\
\hline RDU & $\mathrm{NC}$ & 0.36 & 0.09 & $3.07 * *$ & $0.31 * * *$ & $0.0047 * *$ & $0.29 * *$ & $-0.0074 * * *$ & $-0.44^{* * *}$ \\
\hline OKC & $\mathrm{OK}$ & -0.26 & -0.06 & $2.84 *$ & $0.24 *$ & $0.011 * * *$ & $0.42 * * *$ & -0.0017 & -0.09 \\
\hline TUL & $\mathrm{OK}$ & -0.07 & -0.02 & -0.15 & -0.01 & 0.0003 & 0.01 & $-0.0084 * * *$ & $-0.44 * * *$ \\
\hline CAE & $\mathrm{SC}$ & $-1.99 * * *$ & $-0.39 * * *$ & $-4.27 * *$ & $-0.3 * *$ & 0.0012 & 0.07 & $-0.0156^{* * *}$ & $-0.65 * * *$ \\
\hline CHS & $\mathrm{SC}$ & $-1.54 * * *$ & $-0.36 * * *$ & -0.44 & -0.03 & $0.0083 * * *$ & $0.38 * * *$ & $-0.009 * * *$ & $-0.54 * * *$ \\
\hline GSP & SC & $-1.65^{* *}$ & $-0.27 * *$ & -2.72 & -0.18 & 0.0019 & 0.14 & $-0.0135^{* * *}$ & $-0.53 * * *$ \\
\hline BNA & $\mathrm{TN}$ & -0.54 & -0.12 & 1.41 & 0.11 & $0.0047 * *$ & $0.31 * * *$ & $-0.0121 * * *$ & $-0.6^{* * *}$ \\
\hline CHA & $\mathrm{TN}$ & $-1.34 *$ & $-0.25^{*}$ & 0.25 & 0.02 & $0.0058 * * *$ & $0.35^{* * *}$ & $-0.008^{* * *}$ & $-0.36^{* * *}$ \\
\hline TYS & $\mathrm{TN}$ & -0.3 & -0.06 & 1.78 & 0.15 & $0.0041^{* *}$ & $0.31 * * *$ & $-0.0045^{* *}$ & $-0.3 * *$ \\
\hline AAT & TX & -0.01 & 0 & 2.21 & 0.16 & $0.0056^{*}$ & $0.22 *$ & -0.0037 & -0.21 \\
\hline $\mathrm{ABI}$ & $\mathrm{TX}$ & -0.48 & -0.14 & 0.18 & 0.02 & $0.0051 *$ & $0.22 *$ & $-0.0069 * * *$ & $-0.35^{* * *}$ \\
\hline $\mathrm{ACT}$ & TX & -0.09 & -0.02 & $2.97 *$ & $0.25^{*}$ & $0.0107 * * *$ & $0.47 * * *$ & $-0.0087 * * *$ & $-0.37 * * *$ \\
\hline AMA & TX & -0.58 & -0.18 & -0.2 & -0.03 & 0.003 & 0.14 & $-0.0085^{* * *}$ & $-0.45^{* * *}$ \\
\hline BRO & TX & -0.33 & -0.1 & 0.99 & 0.1 & $0.0063^{*}$ & $0.22 *$ & $-0.0038^{* *}$ & $-0.27^{* *}$ \\
\hline CRP & $\mathrm{TX}$ & $-1.02 *$ & $-0.25^{*}$ & -0.24 & -0.02 & $0.0101 * *$ & $0.31 * * *$ & $-0.005^{* *}$ & $-0.29 * *$ \\
\hline ELP & TX & -0.26 & -0.1 & 0.72 & 0.16 & $0.0079 * * *$ & $0.4 * * *$ & $-0.0078^{* * *}$ & $-0.43^{* * *}$ \\
\hline LBB & $\mathrm{TX}$ & -0.3 & -0.09 & -0.19 & -0.02 & 0.0007 & 0.03 & -0.0032 & -0.14 \\
\hline MAF & TX & -0.59 & -0.18 & -0.55 & -0.07 & 0.0029 & 0.13 & -0.0018 & -0.08 \\
\hline SAT & $\mathrm{TX}$ & -0.62 & -0.12 & 1.62 & 0.12 & $0.0085^{* * *}$ & $0.36 * * *$ & $-0.0037^{*}$ & $-0.23^{*}$ \\
\hline SJT & $\mathrm{TX}$ & -0.36 & -0.12 & 1.63 & 0.18 & $0.0116^{* * *}$ & $0.44 * * *$ & $-0.0067 * * *$ & $-0.37 * * *$ \\
\hline SPS & $\mathrm{TX}$ & -0.21 & -0.06 & -0.18 & -0.02 & 0.0014 & 0.06 & $-0.0094 * * *$ & $-0.47 * * *$ \\
\hline VCT & $\mathrm{TX}$ & 0.21 & 0.04 & 1.52 & 0.08 & -0.0008 & -0.03 & $-0.0086^{* * *}$ & $-0.34 * * *$ \\
\hline
\end{tabular}



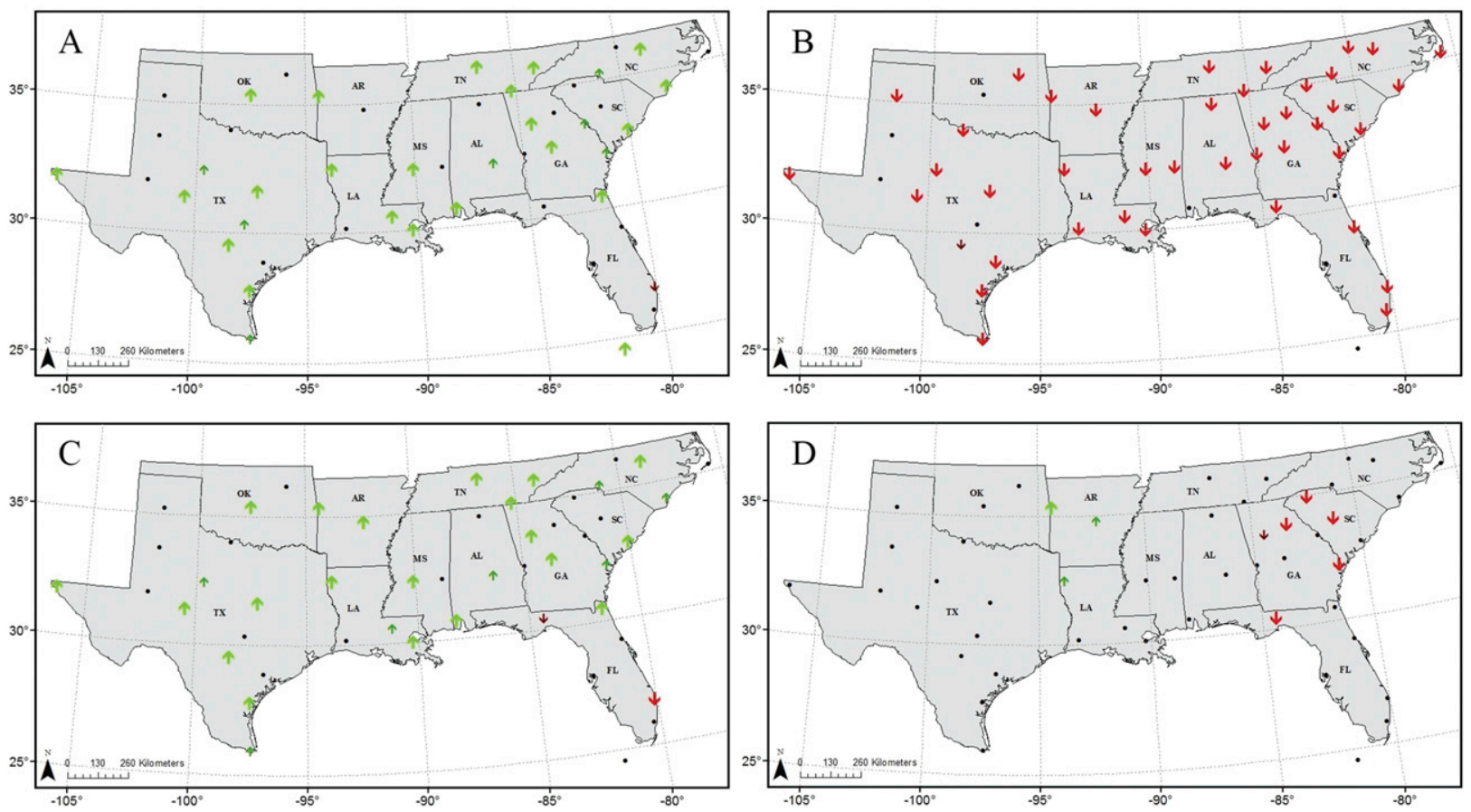

FIG. 11. Trends in (a) hourly intensity, (b) average duration, (c) average hourly totals, and (d) frequency of hourly events above overall station specific average hourly accumulation. Large red arrows represent decreasing trends significant at the $p \leq 0.05$ level; smaller, darker red arrows represent decreasing trends at the $0.05 \leq p \leq 0.10$ level. Large lighter green arrows represent increasing trends significant at the $p \leq 0.05$ level; smaller, darker green arrows represent increasing trends significant at the $0.05 \leq p \leq 0.10$ level.

the frequency of individual precipitation events. If the number of events in a year increases while $\mathrm{PH}$ is held constant, the annual average duration will decrease. For example, if the frequency of hourly traces within precipitation events increases temporally in station time series then precipitation events will be increasingly fragmented, thus artificially increasing the number of precipitation events and lowering durations. To investigate this possible bias, correlation was conducted on the frequency of individual precipitation events and time (year; $n=58$, degrees of freedom $=56$ ) for each station. Results showed 14 stations had significant $(p \leq 0.05)$ correlations, of which 12 were positive (increasing) and 2 were negative (decreasing). Another three stations showed positive correlations significant at $0.05 \leq p \leq 0.10$. This demonstrates that at least part, but not all, of the overall decrease in duration can be attributed to increasing events through time.

Although many trends were significant, it is important to discuss potential limitations. It is possible that slight (nonsignificant) increases in annual totals, which are likely driving the change in annual intensity, are related to better measurement processes; however, no evidence for this was found when viewing residuals. Gauges at first-order stations are updated or replaced periodically; however, the National Weather Service professionally manages these stations and control for systematic biases. This possible bias and other known biases in precipitation measurement (see Legates and DeLiberty 1993; Groisman and Legates 1994) is why PH were used, because $\mathrm{PH}$ are binary, it is either raining or it is not. Using the frequency of $\mathrm{PH}$ and determining trends is likely a less biased approach compared to using accumulations alone. It is also important to understand it is possible that the selected study period is a time of increasing precipitation amount or intensity, imbedded within a larger sinusoidal system with natural upward and downward movements. Nonetheless the spatial coherence and broad agreement in trend directions adds confidence to the results presented.

\section{Key findings and conclusions}

Precipitation totals only describe a small portion of the precipitation climatology of the SeUS. This study has shown that $\mathrm{PH}$, durations, and intensity vary just as much as accumulation across the region. For example, across Louisiana, the wettest state in the conterminous United States (Faiers et al. 1994), roughly 5\% of the annual hours have precipitation, while parts of eastern Tennessee, western North Carolina, and northern Georgia experience close to $7 \%$. It was also found that 

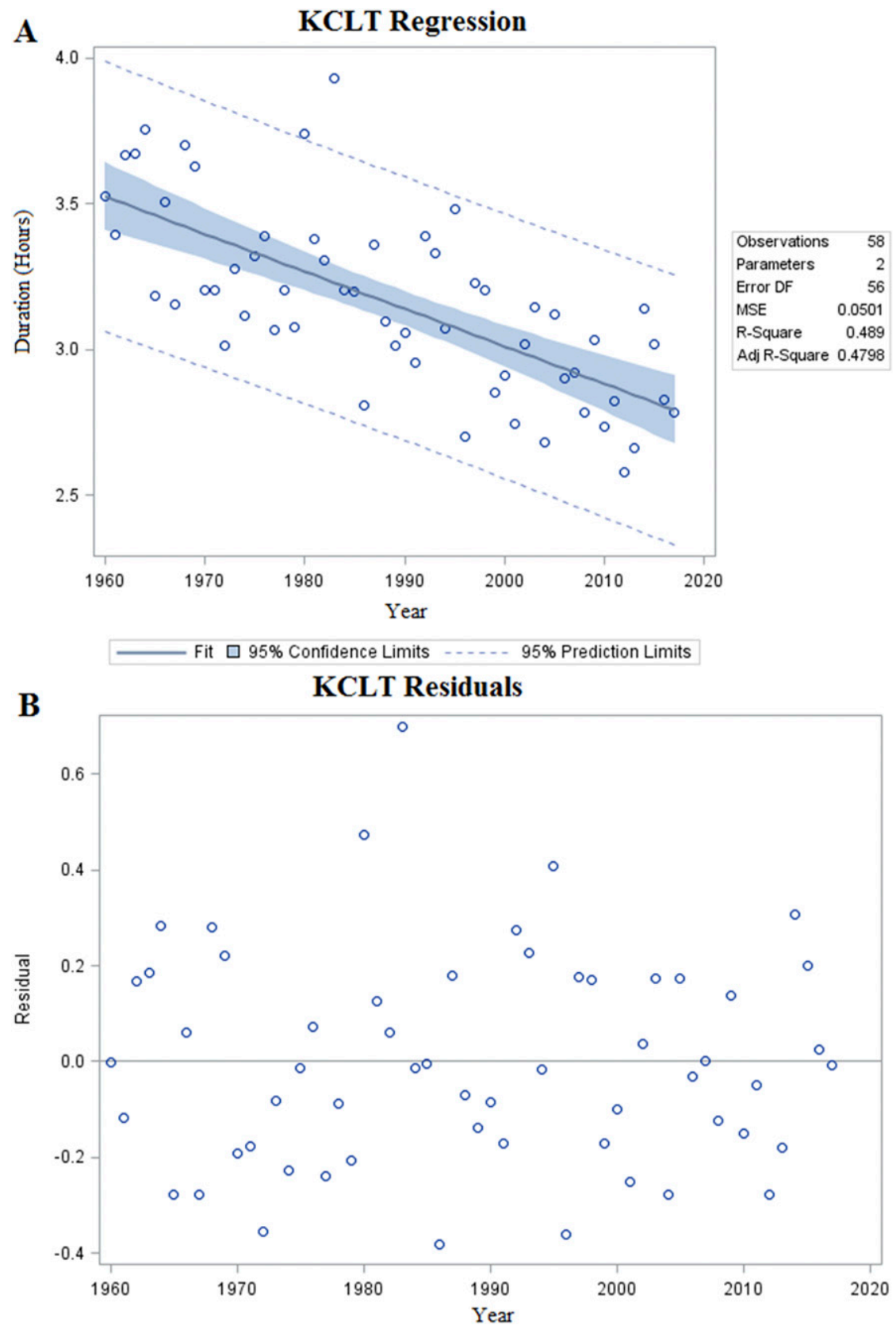

FIG. 12. (a) Regression results for the average annual duration of precipitation events at Charlotte Douglas International Airport, NC, and (b) residuals from the regression. The residuals show no apparent systematic bias.

the frequency of hourly $25.4 \mathrm{~mm}$ ( 1 in.) or greater events is largely confined the Gulf Coast and decreases inland. In all seasons, average hourly totals were highest near the Gulf Coast and Florida, while average durations tended to be below average, further highlighting the intensity of hourly rainfall across this area. Average durations and $\mathrm{PH}$ tended to be highest in the northeastern sector of the region in all seasons, but accumulations tended to be lower excluding mountainous locations with orographically forced precipitation.

Regression tests revealed only five stations had significant increases in annual accumulation through time. $\mathrm{PH}$ showed a different pattern. Thirteen stations, mostly across Georgia, South Carolina, and northern Florida, had significant decreases in annual hours with precipitation. The annual decrease in $\mathrm{PH}$ at these locations was 
attributed to decreases in $\mathrm{PH}$ during spring and winter. The decrease in $\mathrm{PH}$ during spring was accompanied by a decrease in precipitation totals but winter totals did not decrease with $\mathrm{PH}$ at these locations. In summer, eight stations showed significant changes in accumulation, four increasing and four decreasing. PH followed a similar pattern during summer. Finally, in fall, the eastern half of North Carolina and one station in South Carolina showed increases in accumulations. These stations also exhibited increasing trends in $\mathrm{PH}$.

This study also highlighted the increasing intensity and decreasing duration of precipitation across the region. Increases in intensity were found across the entire region and occurred at $44 \%$ of the stations, suggesting that hourly precipitation is becoming more intense. At the same time, the duration of rainfall events was found to be decreasing at $82 \%$ of the stations. These findings are in general agreement with previous research, which describe a changing character of precipitation, favoring more intense events (Trenberth et al. 2003; Powell and Keim 2015; USGCRP 2017). However, it does not appear that heavy hourly events are increasing in frequency broadly across the region like intensity. Rather, it appears that average hourly accumulations are increasing (producing more rainfall).

Steady moderate rainfall tends to soak into the ground and provide a benefit for plants and soils; however, the same rainfall amount in a short period may cause flooding and exacerbate runoff that leaves soils much drier (Trenberth 2011). Heavy and extreme hourly precipitation events are also associated with flash flooding, which often does not get reported (Brooks and Stensrud 2000). If precipitation events continue to decrease in duration and become heavier on average, and current projections anticipate an altered frequency and intensity of weather extremes (Trenberth 2011; Kirtman et al. 2013; USGCRP 2017), thought will need to be given to urban sprawl and the conversion of natural areas to impervious surfaces. If more areas become urbanized while hourly precipitation events become, on average, heavier and shorter in duration, more rainfall will runoff, which will have implications for water quality, the subsurface water table, and flooding. To better manage and adapt to expected changes in the water cycle requires dependable predictions that must be grounded in the changes already observed (Hegerl et al. 2015). Precipitation changes are one of the most important potential outcomes of a warming climate because of how integral it is to society and ecosystems (USGCRP 2017).

Acknowledgments. The authors acknowledge support from NOAA Grant NA13OAR4310183. VMB and BDK also acknowledge support from NOAA Grants NA18OAR4310337 and NA18OAR4310301.

\section{REFERENCES}

Ashley, W. S., T. L. Mote, P. G. Dixon, S. L. Trotter, E. J. Powell, J. D. Durkee, and A. J. Grundstein, 2003: Distribution of mesoscale convective complex rainfall in the United States. Mon. Wea. Rev., 131, 3003-3017, https://doi.org/10.1175/15200493(2003)131<3003:DOMCCR > 2.0.CO;2.

Bell, G. D., and L. F. Bosart, 1988: Appalachian cold-air damming. Mon. Wea. Rev., 116, 137-161, https://doi.org/10.1175/ 1520-0493(1988)116<0137:ACAD>2.0.CO;2.

Bradley, R. S., H. F. Diaz, J. K. Eischeid, P. D. Jones, P. M. Kelly, and C. M. Goodess, 1987: Precipitation fluctuations over Northern Hemisphere land areas since the mid-19th century. Science, 237, 171-175, https://doi.org/10.1126/ science.237.4811.171.

Brooks, H. E., and D. J. Stensrud, 2000: Climatology of heavy rain events in the United States from hourly precipitation observations. Mon. Wea. Rev., 128, 1194-1201, https://doi.org/10.1175/ 1520-0493(2000)128<1194:COHREI > 2.0.CO;2.

Brown, V. M., A. W. Black, and B. D. Keim, 2019: Hourly rainfall climatology of Louisiana. Theor. Appl. Climatol., 137, 20112027, https://doi.org/10.1007/s00704-018-2718-8.

Burauskaite-Harju, A., A. Grimvall, C. Achberger, A. Walther, and D. Chen, 2012: Characterising and visualizing spatio-temporal patterns in hourly precipitation records. Theor. Appl. Climatol., 109, 333-343, https://doi.org/10.1007/s00704-011-0574-x.

Carter, L., and Coauthors, 2018: Southeast. Impacts, Risks, and Adaptation in the United States: Fourth National Climate Assessment, Volume II, D. R. Reidmiller et al., Eds., U.S. Global Change Research Program, 743-808, https://doi.org/10.7930/ NCA4.2018.CH19.

Chen, J., S. Yang, H. W. Li, B. Zhang, and J. R. Lv, 2013: Research on geographical environment unit division based on the method of natural breaks (Jenks). Int. Arch. Photogramm. Remote Sens. Spat. Inf. Sci., XL-4/W3, 47-50, https://doi.org/ 10.5194/isprsarchives-XL-4-W3-47-2013.

Chou, C., C. A. Chen, P. H. Tan, and K. T. Chen, 2012: Mechanisms for global warming impacts on precipitation frequency and intensity. J. Climate, 25, 3291-3306, https://doi.org/10.1175/ JCLI-D-11-00239.1.

Daly, C., G. H. Taylor, and W. P. Gibson, 1997: The PRISM approach to mapping precipitation and temperature. Preprints, 10th Conf. on Applied Climatology, Reno, NV, Amer. Meteor. Soc., 20-23.

Diem, J. E., 2013: Influences of the Bermuda High and atmospheric moistening on changes in summer rainfall in the Atlanta, Georgia region, USA. Int. J. Climatol., 33, 160-172, https:// doi.org/10.1002/joc.3421.

Eck, M. A., L. B. Perry, P. T. Soulé, J. W. Sugg, and D. K. Miller, 2019: Winter climate variability in the southern Appalachian Mountains, 1910-2017. Int. J. Climatol., 39, 206-217, https:// doi.org/10.1002/joc.5795.

Eischeid, J. K., H. F. Diaz, R. S. Bradley, and P. D. Jones, 1991: A comprehensive precipitation dataset for global land areas (TR-051). U.S. Department of Energy Carbon Dioxide Research Program DOE/ER-69017T-H1, TR051, https://doi.org/ 10.3334/CDIAC/cli.tr051.

Emori, S., and S. J. Brown, 2005: Dynamic and thermodynamic changes in mean and extreme precipitation under changed climate. Geophys. Res. Lett., 32, L17706, https://doi.org/ 10.1029/2005GL023272.

Faiers, G. E., B. D. Keim, and K. K. Hirschboeck, 1994: A synoptic evaluation of frequencies and intensities of extreme three-and 
24-hour rainfall in Louisiana. Prof. Geogr., 46, 156-163, https:// doi.org/10.1111/j.0033-0124.1994.00156.x.

Fischer, E. M., and R. Knutti, 2015: Anthropogenic contribution to global occurrence of heavy-precipitation and high-temperature extremes. Nat. Climate Change, 5, 560-564, https://doi.org/ 10.1038/nclimate2617.

Freund, R. J., W. J. Wilson, and D. L. Mohr, 2010: Statistical Methods. 3rd ed. Academic Press, 824 pp.

Fu, S., D. Li, J. Sun, D. Si, J. Ling, and F. Tian, 2016: A 31-year trend of the hourly precipitation over South China and the underlying mechanisms. Atmos. Sci. Lett., 17, 216-222, https:// doi.org/10.1002/asl.645.

Gotvald, A. J., and B. E. McCallum, 2010: Epic flooding in Georgia, 2009. USGS Fact Sheet 2010-3107, 2 pp., https:// pubs.usgs.gov/fs/2010/3107/.

Groisman, P. Ya., and D. R. Easterling, 1994: Variability and trends of total precipitation and snowfall over the United States and Canada. J. Climate, 7, 184-205, https://doi.org/ 10.1175/1520-0442(1994)007<0184:VATOTP >2.0.CO;2.

— cipitation data. Bull. Amer. Meteor. Soc., 75, 215-228, https:// doi.org/10.1175/1520-0477(1994)075<0215:TAOUSP > 2.0.CO;2.

_, R. W. Knight, and T. R. Karl, 2012: Changes in intense precipitation over the central United States. J. Hydrometeor., 13, 47-66, https://doi.org/10.1175/JHM-D-11-039.1.

Hegerl, G. E., and Coauthors, 2015: Challenges in quantifying changes in the global water cycle. Bull. Amer. Meteor. Soc., 96, 1097-1115, https://doi.org/10.1175/BAMS-D-13-00212.1.

Henderson, K. G., and A. J. Vega, 1996: Regional precipitation variability in the southern United States. Phys. Geogr., 17, 93 112, https://doi.org/10.1080/02723646.1996.10642576.

Jenks, G. F., 1967: The data model concept in statistical mapping. International Yearbook of Cartography, Vol. 7, George Philip, 186-190.

Jiang, B., 2013: Head/tail breaks: A new classification scheme for data with a heavy-tailed distribution. Prof. Geogr., 65, 482494, https://doi.org/10.1080/00330124.2012.700499.

Karl, T. R., and W. E. Riebsame, 1989: The impact of decadal fluctuations in mean precipitation and temperature on runoff: A sensitivity study over the United States. Climatic Change, 15, 423-447, https://doi.org/10.1007/BF00240466.

__ , and R. W. Knight, 1998: Secular trends of precipitation amount, frequency, and intensity in the United States. Bull. Amer. Meteor. Soc., 79, 231-242, https://doi.org/10.1175/ 1520-0477(1998)079<0231:STOPAF>2.0.CO;2.

_, P. Y. Groisman, R. W. Knight, and R. R. Heim Jr., 1993: Recent variations of snow cover and snowfall in North America and their relation to precipitation and temperature variations. J. Climate, 6, 1327-1344, https://doi.org/10.1175/ 1520-0442(1993)006<1327:RVOSCA >2.0.CO;2.

Keim, B. D., 1996: Spatial, synoptic, and seasonal patterns of heavy rainfall in the southeastern United States. Phys. Geogr., 17, 313-328, https://doi.org/10.1080/02723646.1996.10642588.

_ 1997: Preliminary analysis of the temporal patterns of heavy rainfall across the southeastern United States. Prof. Geogr., 49, 94-104, https://doi.org/10.1111/0033-0124.00060.

—, A. M. Wilson, C. P. Wake, and T. G. Huntington, 2003: Are there spurious temperature trends in the United States Climate Division database? Geophys. Res. Lett., 30, 1404, https://doi.org/ 10.1029/2002GL016295.

—, W. D. Kappel, G. A. Muhlestein, D. M. Hultstrand, T. W. Parzybok, A. B. Lewis, E. M. Tomlinson, and A. W. Black, 2018: Assessment of the Extreme Rainfall Event at Nashville,
TN and the Surrounding Region on May 1-3, 2010. J. Amer. Water Resour. Assoc., 54, 1001-1010, https://doi.org/10.1111/ 1752-1688.12657.

Kirtman, B., and Coauthors, 2013: Near-term climate change: Projections and predictability. Climate Change 2013: The Physical Science Basis, T. F. Stocker et al., Eds., Cambridge University Press, 953-1028.

Klein, W. H., 1957. Principal tracks and mean frequencies of cyclones and anticyclones in the Northern Hemisphere. U.S. Weather Bureau Research Paper 40, 53 pp.

Kunkel, K. E., 2003: North American trends in extreme precipitation. Nat. Hazards, 29, 291-305, https://doi.org/10.1023/ A:1023694115864.

_, K. Andsager, and D. R. Easterling, 1999: Long-term trends in extreme precipitation events over the conterminous United States and Canada. J. Climate, 12, 2515-2527, https://doi.org/ 10.1175/1520-0442(1999)012<2515:LTTIEP>2.0.CO;2.

— D. R. Easterling, D. A. Kristovich, B. Gleason, L. Stoecker, and R. Smith, 2012: Meteorological causes of the secular variations in observed extreme precipitation events for the conterminous United States. J. Hydrometeor., 13, 1131-1141, https:// doi.org/10.1175/JHM-D-11-0108.1.

_ narios for the U.S. National Climate Assessment: Part 2Climate of the Southeast U.S., NOAA Tech. Rep. NESDIS 142-2, 94 pp., https://www.nesdis.noaa.gov/sites/default/files/ asset/document/NOAA_NESDIS_Tech_Report_142-2-Climate_ of_the_Southeast_US.pdf.

_ extreme storms: State of knowledge. Bull. Amer. Meteor. Soc., 94, 499-514, https://doi.org/10.1175/BAMS-D-11-00262.1.

Legates, D. R., and T. L. DeLiberty, 1993: Precipitation measurement biases in the United States. J. Amer. Water Resour. Assoc., 29, 855-861, https://doi.org/10.1111/j.1752-1688.1993.tb03245.x.

Li, W., L. Li, R. Fu, Y. Deng, and H. Wang, 2011: Changes to the North Atlantic subtropical high and its role in the intensification of summer rainfall variability in the southeastern United States. J. Climate, 24, 1499-1506, https://doi.org/ 10.1175/2010JCLI3829.1.

Li, L., W. Li, and Y. Kushnir, 2012: Variation of the North Atlantic subtropical high western ridge and its implication to Southeastern US summer precipitation. Climate Dyn., 39, 14011412, https://doi.org/10.1007/s00382-011-1214-y.

Maloney, E. D., and Coauthors, 2014: North American climate in CMIP5 experiments: Part III: Assessment of twenty-firstcentury projections. J. Climate, 27, 2230-2270, https://doi.org/ 10.1175/JCLI-D-13-00273.1.

Manuel, J., 2008: Drought in the southeast: Lessons for water management. Environ. Health Perspect., 116, A168, https:// doi.org/10.1289/ehp.116-a168.

Matthews, S. A., 2002: ArcGIS Geostatistical Analyst. GIS Resource Document 02-19.

Maxwell, J. T., and P. T. Soulé, 2009: United States drought of 2007: Historical perspectives. Climate Res., 38, 95-104, https:// doi.org/10.3354/cr00772.

Montgomery, D. C., and E. A. Peck, 1982: Introduction to Linear Regression Analysis. John Wiley and Sons, 504 pp.

Muschinski, T., and J. I. Katz, 2013: Trends in hourly rainfall statistics in the United States under a warming climate. Nat. Climate Change, 3, 577-580, https://doi.org/10.1038/nclimate1828.

NOAA, 2012: Cooperative Program Management and Operations. National Weather Service Instruction 10-1307, 54 pp., https:// www.nws.noaa.gov/directives/sym/pd01013007curr.pdf. 
_ 2016: Hourly precipitation data documentation. 5 pp., https:// www1.ncdc.noaa.gov/pub/data/cdo/documentation/PRECIP HLY_documentation.pdf.

Nogueira, R. C., and B. D. Keim, 2010: Annual volume and area variations in tropical cyclone rainfall over the eastern United States. J. Climate, 23, 4363-4374, https://doi.org/10.1175/ 2010JCLI3443.1.

__ and __, 2011: Contributions of Atlantic tropical cyclones to monthly and seasonal rainfall in the eastern United States 1960-2007. Theor. Appl. Climatol., 103, 213-227, https:// doi.org/10.1007/s00704-010-0292-9.

,-- D. P. Brown, and K. D. Robbins, 2013: Variability of rainfall from tropical cyclones in the eastern USA and its association to the AMO and ENSO. Theor. Appl. Climatol., 112, 273-283, https://doi.org/10.1007/s00704-012-0722-y.

Oliver, M. A., and R. Webster, 1990: Kriging: A method of interpolation for geographical information systems. Int. J. Geogr. Inf. Syst., 4, 313-332, https://doi.org/10.1080/ 02693799008941549.

Ozturk, D., and F. Kilic, 2016: Geostatistical approach for spatial interpolation of meteorological data. An. Acad. Bras. Cienc., 88, 2121-2136, https://doi.org/10.1590/00013765201620150103.

Powell, E. J., and B. D. Keim, 2015: Trends in daily temperature and precipitation extremes for the southeastern United States: 1948-2012. J. Climate, 28, 1592-1612, https://doi.org/10.1175/ JCLI-D-14-00410.1.

Prein, A. F., R. M. Rasmussen, K. Ikeda, C. Liu, M. P. Clark, and G. J. Holland, 2017: The future intensification of hourly precipitation extremes. Nat. Climate Change, 7, 48-52, https:// doi.org/10.1038/nclimate3168.

Rackley, J. A., and J. A. Knox, 2016: A climatology of southern Appalachian cold-air damming. Wea. Forecasting, 31, 419432, https://doi.org/10.1175/WAF-D-15-0049.1.

Robinson, P. J., and K. G. Henderson, 1992: Precipitation events in the south-east United States of America. Int. J. Climatol., 12, 701-720, https://doi.org/10.1002/joc.3370120704.

Rogers, J. C., 2013: The 20th century cooling trend over the southeastern United States. Climate Dyn., 40, 341-352, https:// doi.org/10.1007/s00382-012-1437-6.

Shapiro, S. S., and M. B. Wilk, 1965: An analysis of variance test for normality (complete samples). Biometrika, 52, 591-611, https://doi.org/10.2307/2333709.

Simpson, R. H., and H. Riehl, 1981: The Hurricane and Its Impact. Louisiana State University Press, 398 pp.

Skeeter, W. J., J. C. Senkbeil, and D. J. Keellings, 2019: Spatial and temporal changes in the frequency and magnitude of intense precipitation events in the southeastern United States. Int. J. Climatol., https://doi.org/10.1002/joc.5841.

Thorp, J. M., and B. C. Scott, 1982: Preliminary calculations of average storm duration and seasonal precipitation rates for the northeast sector of the United States. Atmos. Environ., 16, 1763-1774, https://doi.org/10.1016/0004-6981(82)90269-4.

Trenberth, K. E., 1998: Atmospheric moisture residence times and cycling: Implications for rainfall rates and climate change. Climatic Change, 39, 667-694, https://doi.org/10.1023/A: 1005319109110.

- 2011: Changes in precipitation with climate change. Climate Res., 47, 123-138, https://doi.org/10.3354/cr00953.

, and Y. Zhang, 2017: How often does it really rain? Bull. Amer. Meteor. Soc., 99, 289-298, https://doi.org/10.1175/ BAMS-D-17-0107.1.

, A. Dai, R. M. Rasmussen, and D. B. Parsons, 2003: The changing character of precipitation. Bull. Amer. Meteor. Soc., 84, 1205-1217, https://doi.org/10.1175/BAMS-84-9-1205.

_- Y. Zhang, and M. Gehne, 2017: Intermittency in precipitation: Duration, frequency, intensity, and amounts using hourly data. J. Hydrometeor., 18, 1393-1412, https://doi.org/ 10.1175/JHM-D-16-0263.1.

United States Department of Agriculture, 2016: Climate risks in the Southeast. USDA Regional Climate Hubs Factsheet, 2 pp., https://www.usda.gov/oce/climate_change/hubs/ SoutheastFactSheet.pdf.

USGCRP, 2014: Climate Change Impacts in the United States: The Third National Climate Assessment. J. M. Melillo, T. C. Richmond, and G. W. Yohe, Eds., U.S. Global Change Research Program, 841 pp., https://doi.org/10.7930/J0Z31WJ2. 2017: Climate Science Special Report: Fourth National Climate Assessment, Volume I. D. J. Wuebbles et al., Eds., U.S. Global Change Research Program, 470 pp, https://doi.org/ 10.7930/J0J964J6.

Waller, L. A., and C. A. Gotway, 2004: Applied Spatial Statistics for Public Health Data. John Wiley \& Sons, 520 pp.

Wang, G., D. Wang, K. E. Trenberth, A. Erfanian, M. Yu, M. G. Bosilovich, and D. T. Parr, 2017: The peak structure and future changes of the relationships between extreme precipitation and temperature. Nat. Climate Change, 7, 268-274, https://doi.org/10.1038/nclimate3239.

Whittaker, L. M., and L. H. Horn, 1984: Northern Hemisphere extratropical cyclone activity for four mid-season months. J. Climatol., 4, 297-310, https://doi.org/10.1002/joc.3370040307.

Zhu, J., and X. Z. Liang, 2013: Impacts of the Bermuda high on regional climate and ozone over the United States. J. Climate, 26, 1018-1032, https://doi.org/10.1175/JCLI-D-12-00168.1.

Zolina, O., C. Simmer, S. K. Gulev, and S. Kollet, 2010: Changing structure of European precipitation: longer wet periods leading to more abundant rainfalls. Geophys. Res. Lett., 37, L06704, https://doi.org/10.1029/2010GL042468.

- _ - K. Belyaev, S. K. Gulev, and P. Koltermann, 2013: Changes in the duration of European wet and dry spells during the last 60 years. J. Climate, 26, 2022-2047, https://doi.org/ 10.1175/JCLI-D-11-00498.1. 